\title{
Pathways to well-being: Untangling the causal relationships among biopsychosocial variables
}

\author{
N. Karunamuni ${ }^{1 *}$, I. Imayama ${ }^{2}$, D. Goonetilleke ${ }^{3}$
}

${ }^{1}$ Centre for Healthy Communities, School of Public Health, University of Alberta, 3-300 Edmonton Clinic Health Academy, 11405 - 87 Ave, Edmonton, Alberta, Canada.

${ }^{2}$ Division of Pulmonary, Critical Care, Sleep and Allergy, University of Illinois at Chicago, 840 S Wood St. MC719, Chicago, IL, 60612, USA

${ }^{3}$ Minnesota State University, Mankato, Department of Counseling and Student Personnel, 107 Armstrong Hall, Mankato, MN 56001, USA

*Corresponding author:

Nandini D. Karunamuni

E-mail: nandini@ualberta.ca

[The final format of this article is published in the journal Social Science \& Medicine. Article doi: https://doi.org/10.1016/j.socscimed.2020.112846 ] 


\section{Introduction}

The biopsychosocial (BPS) model of health and illness proposed by George L. Engel (1913-1999) is a popular interdisciplinary framework (Engel, 1977) that remains influential today (Davies and Roache, 2017; Johnson and Acabchuk, 2018). This model challenged and broadened the historically dominant biomedical model by taking into consideration biological and social factors as well as an individual's lived experiences (i.e., psychological factors relevant to an individual) that can influence health and illness (Davies and Roache, 2017; Wade and Halligan, 2017). While the BPS model currently serves as a useful clinical and teaching function in medicine and its heuristic implications appears to have reached general agreement (Davies and Roache, 2017; Wade and Halligan, 2017), a growing body of literature has been highly critical of the model for being too vague, and for not providing details as to how BPS factors interact to influence health and illness (Benning, 2015; Farre and Rapley, 2017; Ghaemi, 2010). The purpose of this article is to provide a careful examination of interrelationships among biological, psychological, and social factors as well as how these factors contribute to health and illness.

In proposing the BPS model, although Engel (1977) emphasized the importance of taking into consideration BPS factors as contributory factors for health and illness, he did not identify a specific measure of health that these variables could impact. Considering that the BPS model emphasizes the importance of taking into account an individual's inner (subjective) experience within his or her life context (Engel, 1980; Wade and Halligan, 2017), this article will investigate how biological, psychological, and social factors contribute to subjective well-being (SWB) as the primary health outcome. 
Since SWB takes into account mental health variables such as depression and anxiety, which are not typically considered by objective physical health indicators (Cross et al., 2018), we think SWB is an especially suitable outcome measure for the BPS model.

According to the research literature, SWB is a multidimensional construct and a broad umbrella term that refers to numerous ways of evaluating one's life or emotional experiences, and it includes components such as negative/positive affect, satisfaction and measures of eudaimonic wellbeing (for an overview of SWB, see: Cross et al., 2018; Diener et al., 2017a; Ryff, 2018). For the purpose of this article, we will define SWB as a self-rated assessment of well-being in which an individual takes into consideration any events, circumstances, or experiences he or she is facing at the present point in life. We make this definition considering that SWB is a dynamic construct that can change any time as a result of one's changing circumstances such as being diagnosed with a terminal illness, losing a loved one, achieving or being unable to achieve a life goal (Diener et al., 2017b; Lehman et al., 2017; Lucas et al., 2007; Luhmann et al., 2012).

This article will also consider physical health—which can be assessed using a variety of methods for numerous concerns - as another outcome variable, since this makes the model more broadly generalizable. Physical health is generally objectively measured and evaluated as an indicator of normal biologic processes (Kumar et al., 2015; Fuller, 2017). It is also useful to note that the association between objective physical health and SWB appears to be strong (Cross et al., 2018; Diener et al., 2018a; Howell et al., 2007).

The BPS model has its roots in the general systems theory (Engel, 1980; von Bertanlaffy, 1975), which provides a conceptual framework within which both organized 
wholes and component parts can be studied. Engel explains that methods and rules distinctive for the study and understanding of one 'system' (for example, the study of cells) cannot be applied for the study of another system (for example, the study of communities) although one system could influence another system (Engel, 1980). Adopting this idea, we will consider biological, psychological, and social factors to be distinct 'systems' that have different qualities and rules operating within each system, but at the same time could influence one another, and also contribute to the psychological construct, SWB as well as to physical health. Here, we will consider biological factors to constitute an individual's physical body along with its organs (that can be understood at a molecular, cellular, and an organizational level); the psychological factors to be an individual's lived (subjective) experiences which constitutes mental states such as negative/positive affect, perceptions, goals, attitudes, views, intentions and behavior; and social factors to constitute life events, interpersonal experiences, social policies, social circumstances, sociocultural influences and so forth that influence an individual. Note that this conceptualization is slightly different from the original general systems theory that considers a hierarchy of units that happen in a continuum (Engel, 1980; von Bertanlaffy, 1975). Yet, the whole of the 'organismic hierarchy' can be considered as representing biological factors, the whole of the 'social hierarchy' can be considered as representing social factors and the person-level factors can be understood as representing psychological factors.

The objectives of this article are to use analytical reasoning and critically examine relevant research literature to explore how biological, psychological, and social factors applicable to an individual directly and causally relate to each other, as well as to 
investigate how these factors could contribute to SWB and to physical health outcomes. We will also examine how understanding subjective experience can explain individual differences in causal pathways and then present the BPS-Pathways model. Implications of the BPS-Pathways model for clinical practice will also be discussed.

\section{Biological, psychological and social factors: Exploring interrelationships}

When considering biological, psychological, and social factors separately, we can broadly conceptualize various influences that can bring about changes in these factors. Biological factors (that constitute the physical body, and is often described in the language of the basic biomedical sciences, including anatomy, physiology, and molecular biology) can for example be affected by infections, injuries, diet, exposure to toxins, genetic influences, various debilitating functioning abnormalities, etc., and these causes can often be further linked to a multitude of other causes. When considering psychological factors, these are also affected by numerous causes including sociocultural influences and demographic factors. In terms of social factors, changes in social organization, social norms, migration, and innovation along with a host of other causes can bring about changes in these factors. In this regard, comprehensive research in subject areas of biology, psychology, and sociology (as well as their sub-disciplines) explore numerous influences and various associations at many different levels.

In this article, we focus on direct causal associations among biological, psychological, and social factors as well as their contribution to SWB and objective physical health. Although biological, psychological, and social factors represent heterogeneous categories of factors, these factors can be conceptually separated and 
defined (as described in the Introduction section), and each of these factors can also be measured using reliable and valid scales or questionnaires. For example, biological factors can be measured through biomarkers, DNA methylation patterns, changes in neural networks and their interconnections, as well as through numerous objective health measures (that directly or indirectly relate to biological factors). Psychological factors can be assessed through instruments, measures, and scales relating to constructs such as SWB, perceived stress, anxiety, perceptions, intentions, and goals. Social factors can be assessed using measures of socioeconomic status, the frequency of contacts with friends and relatives, the presence of a life event, the availability of a community service, etc. Further, causative influences among these measurable BPS factors can also be examined. Examples include studying how the psychological process of learning (changes in perceptions) brings about changes in neural networks, and how the social factor of being lonely results in changes in circulating levels of inflammatory markers.

When considering biological (B), psychological (P) and social (S) factors as they apply to a single individual, six potential direct causal pathways can occur among these three factors [see Table 1 and Figure 1, section (i)]. These are biological factors causally influencing psychological factors (the $\mathrm{B} \rightarrow \mathrm{P}$ pathway), psychological factors causally influencing biological factors (the $\mathrm{P} \rightarrow \mathrm{B}$ pathway), social factors causally influencing psychological factors (the $\mathrm{S} \rightarrow \mathrm{P}$ pathway), psychological factors causally influencing social factors (the $\mathrm{P} \rightarrow \mathrm{S}$ pathway), biological factors causally influencing social factors (the $\mathrm{B} \rightarrow \mathrm{S}$ pathway), and social factors causally influencing biological factors (the $\mathrm{S} \rightarrow \mathrm{B}$ pathway). We will also denote pathways that are investigated by broad subject areas of biology, psychology, and sociology as $\mathrm{B} \rightarrow \mathrm{B}, \mathrm{P} \rightarrow \mathrm{P}$ and $\mathrm{S} \rightarrow \mathrm{S}$ pathways respectively. 
Table 1. The six direct causal pathways that can happen between each of the three BPS factors.*

\begin{tabular}{cl}
\hline Pathway & \multicolumn{1}{c}{ Description } \\
\hline $\mathrm{B} \rightarrow \mathrm{P}$ & Biological factors causally influencing psychological factors \\
$\mathrm{P} \rightarrow \mathrm{B}$ & Psychological factors causally influencing biological factors \\
$\mathrm{S} \rightarrow \mathrm{P}$ & Social factors causally influencing psychological factors \\
$\mathrm{P} \rightarrow \mathrm{S}$ & Psychological factors causally influencing social factors \\
$\mathrm{B} \rightarrow \mathrm{S}$ & Biological factors causally influencing social factors \\
$\mathrm{S} \rightarrow \mathrm{B}$ & Social factors causally influencing biological factors \\
& \\
\hline
\end{tabular}

*Biological factors (B), constitute an individual's physical body along with its organs that can be understood at a molecular, cellular, and an organizational level; psychological factors (P) constitute an individual's lived (subjective) experiences which encompass mental states such as negative/positive affect, perceptions, goals, attitudes, views, intentions and behavior; social factors (S) constitute life events, interpersonal experiences, social policies, social circumstances and sociocultural influences, etc., that an individual can be subjected to.

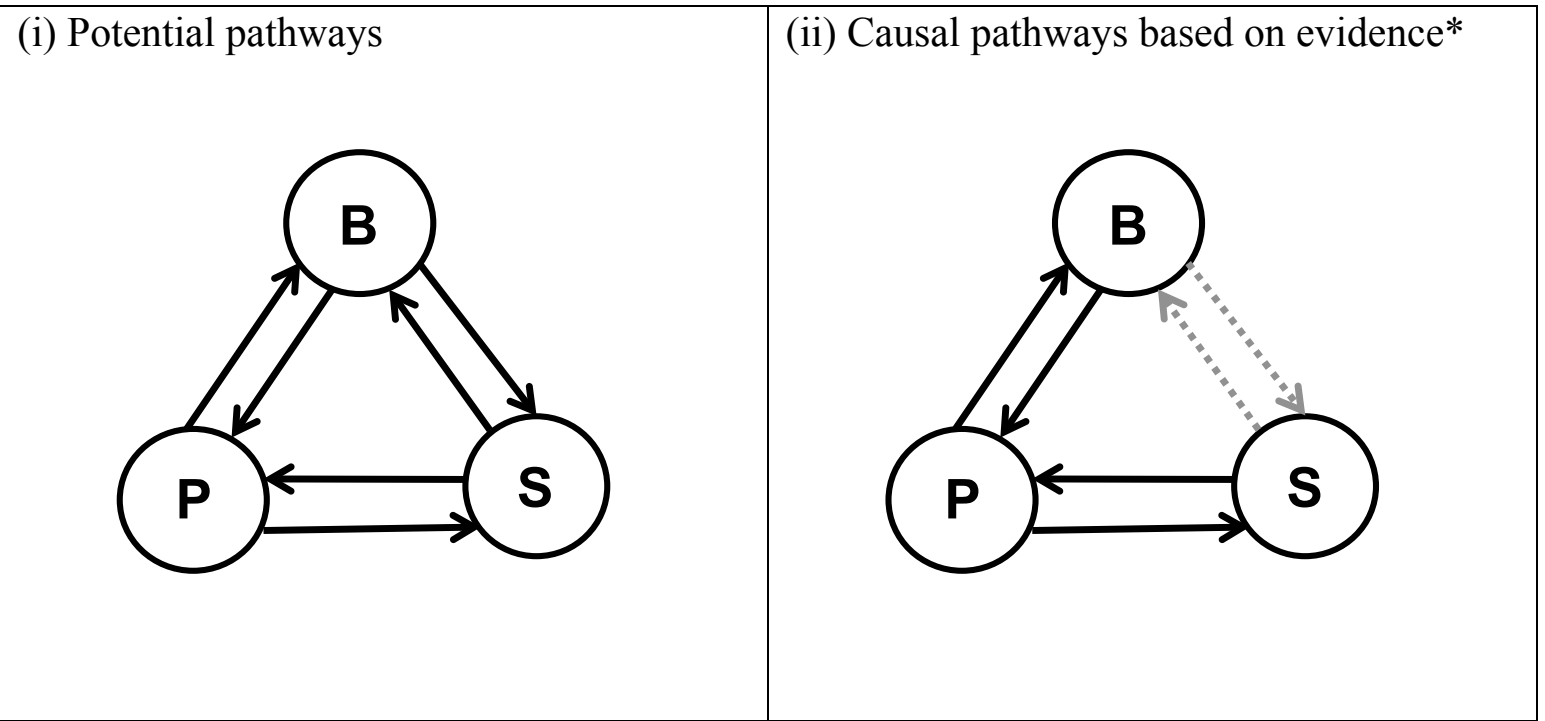

Fig 1. Pathways among biological (B), psychological (P) and social (S) factors. *Direct $\mathrm{S} \rightarrow \mathrm{B}$ and $\mathrm{B} \rightarrow \mathrm{S}$ pathways (that are not mediated by psychological factors) are indicated by gray dotted lines. 
Because it is beyond the scope of this article to carry out a comprehensive review of the literature relating to each of the above pathways, we located most recent systematic reviews, meta-analyses and narrative review articles that have already critically presented causal directions among BPS factors, and also had a health-related focus (i.e., review articles that took into consideration evidence stemming from epidemiological investigations including prospective, longitudinal cohort studies, and case-control studies along with laboratory experiments and animal studies). We also examined the most recent review updates on subject areas that have a cross-disciplinary focus, such as "psychoneuroimmunology," "neuroplasticity," "social neuroscience," “epigenetics," and "placebo/nocebo effects." Guided by these reviews, we constructed a search strategy to locate recent systematic reviews, meta-analyses, and narrative reviews around the themes that included: "psychological stress," "social factors," "social environment," "environmental enrichment," "hypothalamus-pituitary-adrenal axis," "inflammation," and "rumination." Forward citation tracking was also conducted to identify the most recent reviews. All searches were conducted in electronic databases including MEDLINE, Google Scholar, Web of Science, Embase and Scopus.

Deliberating evidence supporting each of the six pathways mentioned above, we will examine research corroborating each pathway and conduct analytical reasoning on how these pathways relate to each other and contribute to SWB as well as to measures of objective health. 


\section{The $B \rightarrow P$ pathway}

The B $\rightarrow$ P pathway considers how biological factors can contribute to psychological factors, including SWB. Extending from the traditional biomedical model, "good" objective physical health is often described as the systems of the physical body carrying out physiological functions properly, resulting in the lack of illness or disease (Cross et al., 2018; Idler and Kasl, 1991). When considering the B $\rightarrow$ P pathway, research suggests changes in physical health conditions can significantly influence various aspects of SWB including positive and negative affect as well as life satisfaction (Diener et al., 2017a; Diener et al., 2018a; Steptoe et al., 2015). Further, studies that have examined a broad range of health conditions in large, representative samples indicate different health conditions can influence SWB to different degrees (Diener et al., 2018a; Steptoe et al., 2015), and that disabling conditions (especially those that are more severe or those that have a strong effect on mobility) are associated with relatively large decrements in positive affect (Diener et al., 2018a). Physical pain and discomfort, which can be associated with several physical health conditions, also appear to negatively impact SWB (OECD, 2013). All of these represent the B $\rightarrow$ P pathway.

Preventive measures that protect the physical body such as having access to shelter, a nutritious diet, water, and medical care/insurance as well as being protected from toxins and being able to minimize risks associated with genetic health conditions, etc., are situations where biological pathways operate (i.e., B $\rightarrow$ B pathways), and these can subsequently impact the B $\rightarrow$ P pathway (i.e., bring about changes in various aspects of an individual's SWB; Diener et al., 2017b; Diener et al., 2018b). 


\section{The $P \rightarrow B$ pathway}

The $\mathrm{P} \rightarrow \mathrm{B}$ pathway considers the causal influence of psychological factors on biological factors including indicators of objective physical health. In this regard, numerous studies have explored the influence of a variety of psychological factors (including negative/positive affect, perceptions, intentions, and behaviour) on biological factors, although many studies have focused on the influence of negative affect (i.e., feelings of anger, sadness, stress, worry, and depression; Diener et al., 2017a) on indicators of objective physical health.

Several experimental, ambulatory, and longitudinal studies have demonstrated that positive measures of SWB (measured through increased positive affect, decreased negative affect, and satisfaction) have a large effect on objective physical health (Howell et al., 2007; Diener et al., 2018a), and that positive measures of SWB are linked to greater longevity and reduced mortality (Cross et al., 2018; De Neve et al., 2013; Diener et al., 2018a; Howell et al., 2007; Steptoe et al., 2015). Longitudinal studies have demonstrated that the effect of SWB on health is not solely due to ill-being having a detrimental impact on health, but also to SWB having a salutary impact on health (Howell et al., 2007). Further, long-term interventions to raise SWB (decreasing negative affect and increasing positive affect) have been found to influence various physical health outcomes (Diener et al., 2018a).

Data from epidemiologic prospective studies indicate that negative affect can provoke the activation of the sympathetic nervous system and the hypothalamuspituitary-adrenal axis (HPA), resulting in a cascade of physiological events and a spectrum of biological clinical manifestations (Hänsel et al., 2010; Johnson and 
Acabchuk, 2018; Liu et al., 2017; Russell et al., 2018; Steptoe et al., 2007; Straub and Cutolo, 2018). In this regard, the interdisciplinary field of psychoneuroimmunology that explores the interaction between psychological processes and the nervous and immune systems is backed by close to five decades of research (Bottaccioli et al., 2019; KiecoltGlaser, 2009; Straub and Cutolo, 2018). The physiological and clinical manifestations that result from negative affect include elevated pro-inflammatory cytokine levels that have the potential to influence the development of a variety of physical health conditions such as coronary artery disease, diabetes, certain types of cancers, metabolic syndrome, autoimmune diseases, neuropsychiatric disorders and other chronic conditions (Acabchuk et al., 2017; Kelly and Ismail, 2015; Liu et al., 2017; Wirtz and von Känel, 2017).

A growing number of studies have also explored the impact of induced psychological stress on circulating markers of inflammation using experimental protocols. Recent meta-analyses of such studies have demonstrated reliable increases in markers of inflammation following induced laboratory stress (Marsland et al., 2017; Slavish et al., 2015). Further, studies have demonstrated that stress-related physiological manifestations can be reversed when psychological stress or other negative emotions are addressed (Black and Slavich, 2016; Finn and Fancourt, 2018; Hulett and Armer, 2016; Lopresti, 2017; Slopen et al., 2014) providing further evidence for the $\mathrm{P} \rightarrow \mathrm{B}$ pathway.

Neuroscience research within the last few decades has confirmed that the organization of brain circuitry is constantly changing as a function of various psychological experiences, where biological changes can range from the cellular level to cortical remapping (Fuchs and Flügge, 2014; McEwen, 2016; Sale et al., 2014), and this 
phenomenon (referred to as neuroplasticity) provide additional evidence for the $\mathrm{P} \rightarrow \mathrm{B}$ pathway. For example, research has demonstrated that psychological factors such as learning a new motor or perceptual ability or forming a spatial map of a new geographic area mentally, brings about changes in neural circuits (McEwen, 2016; Sale et al., 2014). Other types of psychological experiences such as the development of socially conditioned preferences, intentions, beliefs, and even the acquisition of self-control, also bring about changes in the brain (Corlett and Marrouch, 2018; Davidson and McEwen, 2012; Park and Huang, 2010; Sale et al., 2014; Shaffer, 2016). When considering psychological stress, numerous animal and human studies have consistently demonstrated that psychological stress causes observable structural changes in the brain (Bender et al., 2016; Davidson and McEwen, 2012; McEwen, 2018; Ortiz and Conrad, 2018), and that these changes have the potential to reverse when stress is removed or when negative emotions are addressed (Boyd et al., 2018; Davidson and McEwen, 2012; Kristensen et al., 2018; Lueken, and Hahn, 2016; Sankar et al., 2018).

In the field of epigenetics, it has been demonstrated that psychological stress can lead to modifications in DNA methylation patterns, resulting in changes in genetic expression, which can subsequently lead to long-term health-related adverse effects (Gray et al., 2017; McEwen, 2018; Mulligan, 2016). Other studies indicate that these molecular processes are reversed when psychological stress or other negative emotions are managed or eliminated (Bottaccioli et al., 2019; Feinstein and Church, 2010; Househam et al., 2017; Kanherkar et al., 2017; Stahl, 2012). The $\mathrm{P} \rightarrow \mathrm{B}$ pathway is further validated by these findings. 
The $\mathrm{P} \rightarrow \mathrm{B}$ pathway is also strongly supported by powerful placebo and nocebo effects. Placebo effects involve measurable changes in physiology, symptoms, and clinical outcomes including changes in patterns of neural activity as a result of expectancies and prior learning about the success of an intervention (Ashar et al., 2017; Petrie and Rief, 2019). Nocebo effects (which are the opposite of placebo effects) occur when a person anticipates negative effects from a treatment (Evers et al., 2018; Petrie and Rief, 2019). These negative expectations can also manifest in unexpected ways. One large longitudinal study (that adjusted for relevant covariates) found those holding more negative age stereotypes (such as holding the view that old people are absent minded) earlier in life, to have significantly larger hippocampal-volume loss and greater accumulation of amyloid plaques (Levy et al., 2016). Further, a recent randomized study demonstrated that learning of one's genetic risk could contribute to a more powerful physiological risk than the risk related to having that genotype (Turnwald et al., 2019). Psychological and physical behaviour also contribute to biological factors. Once an individual experiences a psychological stressor, the psychological habit (behavior) of repeatedly dwelling on thoughts relating to the stressful incident (i.e., habit of rumination) has been shown to intensify the physiological effects of the stressor, leading to continual activation of the HPA axis (Grierson et al., 2016; Lyubomirsky et al., 2015; Verkuil et al., 2010; Zoccola and Dickerson, 2012). This is another important $\mathrm{P} \rightarrow \mathrm{B}$ pathway. A large number of studies indicate that rumination causally contributes to the onset, maintenance, or recurrence of a multitude of mental disorders (Grierson et al., 2016; Law and Tucker, 2017; Watkins, 2015; Zoccola and Dickerson, 2012) as well as a 
host of adverse physical health outcomes (Busch et al., 2017; Lyubomirsky et al., 2015; Querstret and Cropley, 2013; Verkuil et al., 2010).

Various psychological factors including attitude, intention, and self-efficacy can influence individuals to engage in health-related behaviours that can activate numerous $\mathrm{B} \rightarrow \mathrm{B}$ pathways. In this regard, a considerable body of evidence has linked the development of chronic physical health conditions to health harming behaviours (such as smoking and inactivity) as well as health-promoting behaviours (e.g., exercising, healthy eating) to health benefits (Bauer et al., 2014; Glanz et al., 2008).

\section{The $S \rightarrow P$ and $P \rightarrow S$ pathways}

The $\mathrm{S} \rightarrow \mathrm{P}$ pathway and the $\mathrm{P} \rightarrow \mathrm{S}$ pathway are discussed together because psychological factors can both be influenced by as well as influence social factors: a concept known as reciprocal determination (Bandura, 1986; Glanz et al., 2008). Numerous longitudinal, experimental and other investigations support the $\mathrm{S} \rightarrow \mathrm{P}$ pathway, where it has been demonstrated that social factors such as life events, interpersonal experiences, social policies, social circumstances, and sociocultural conditioning influences can contribute to psychological factors in different ways, and thereby influence individuals' short- and long-term SWB (Diener et al., 2017b; Haslam et al., 2019; Luhmann et al., 2012). Examples of life events that can impact SWB include the death of a loved one, divorce, abuse, being bullied, unemployment, and relocation (Diener et al., 2017b; Luhmann et al., 2012). In terms of interpersonal experiences, a large body of evidence points the stress-buffering effects of social belonging and social support (Glanz et al., 2008; Hostinar et al., 2014). Other studies have demonstrated 
unfavorable effects of interpersonal experiences that include social exclusion, being subject to criticism and domination, which can negatively impact an individual's SWB (Glanz et al., 2008; Rook, 2015).

By comparing the SWB of citizens between countries and within countries over time, researchers have revealed insights into various social policies that make for a happier nation (see Diener et al., 2017b; Diener et al., 2018b; for reviews). Here, factors that contribute to a higher SWB (such as higher positive affect and satisfaction) include having governments that are efficient and relatively less corrupt, where the rule of law, human rights, and political freedoms are well protected, and where citizens are satisfied with public services and can rely on greater unemployment benefits (Diener et al., 2017b; Diener et al., 2018b). Social circumstances could also have an impact on an individual's psychological factors. For example, relative poverty (as measured by comparison to other households in the community) appears to exert a greater influence on SWB than absolute poverty (Chen, 2015; Diener et al., 2017b; Diener et al., 2018b). Sociocultural conditioning influences have a large impact in shaping an individual's psychological factors such as views and opinions an individual holds towards various domains in life (Kashima et al., 2019). (These influences will be further explored under the subsection "The significance of understanding subjective experience.")

In terms of the $\mathrm{P} \rightarrow \mathrm{S}$ pathway, psychological factors can also bring about changes in social factors. For example, studies indicate that positive affect can lead to social relationships and negative affect can influence perception of problems and social conflicts (Diener et al., 2017a; Moore et al., 2018). Additionally, an individual or a group of individuals can bring about changes in social norms and behaviors at a population 
level. Examples include bringing about changes in public attitudes on potentially health influencing global phenomena (such as climate change; Lewandowsky et al., 2019) that can result in changes in social norms ( $\mathrm{P} \rightarrow \mathrm{S}$ pathway), which in turn can shape individuals' future intentions and behaviour ( $\mathrm{S} \rightarrow \mathrm{P}$ pathway). Further, bringing about changes in public perceptions about a particular disease ( $\mathrm{P} \rightarrow \mathrm{S}$ pathway) can lead to greater social acceptance of a disease condition (Heijnders and Van Der Meij, 2006) ultimately potentially contributing to the SWB in an individual suffering from that disease ( $\rightarrow$ P pathway).

\section{The $S \rightarrow$ B pathway}

The $\mathrm{S} \rightarrow$ B pathway considers the causal influence of social factors on biological factors. Research on environmental enrichment involving numerous animal and human studies have consistently demonstrated that enhanced stimulation provided at multiple cognitive, sensory, social, and motor levels dramatically influences brain morphology, chemistry, and physiology (Alwis and Rajan, 2014; Sale et al., 2014; Yu et al., 2016). Other studies report how social influences such as subjective social status, interpersonal stresses, feelings of social disconnection, and loneliness contribute to adverse health outcomes by causing changes in various biological markers, which can lead to dysregulation across multiple physiological systems that underlies chronic diseases (Acabchuk et al., 2017; Cole, 2013; Haslam et al., 2019; Miller, 2011; Uchino et al., 2018). Additional evidence for the $S \rightarrow B$ pathway come from a large number of studies including large-scale epidemiological investigations that have shown early childhood experiences including trauma, strongly predict a higher vulnerability to develop physical 
and mental health issues later on in life (Davidson and McEwen, 2012; Kessler et al., 2010; Varese et al., 2012).

It should also be noted that social influences could motivate an individual to engage in health promoting or health harming behaviors (Glanz et al., 2008). As discussed earlier (under the subsection $\mathrm{P} \rightarrow \mathrm{B}$ pathway), such influences could have a large impact on physical health. These physical health benefits can also contribute to an individual's SWB. Under the subsection "The significance of understanding subjective experience," we will discuss how the S $\rightarrow$ B pathway appears to be mediated by psychological factors.

\section{The $B \rightarrow$ S pathway}

This pathway considers how biological factors can influence social factors. In terms of this pathway, it is possible to speculate that changes in biological factors such as an illness, brain injury, etc., can bring about changes in an individual's subjective experience (i.e., psychological factors including intentions and behaviour), and these can affect different aspects of SWB of an individual (as described in discussing the $\mathrm{B} \rightarrow \mathrm{P}$ pathway), and this could in turn influence social factors (e.g., social involvements that result in social influences). In this regard, research suggests that individuals having a higher SWB are more likely to engage in healthy behaviors such as exercising, not smoking, and wearing seat belts, or factors that can additionally contribute to their physical health and SWB (Diener et al., 2017a, b; Diener et al., 2018b). In other words, since the influence of biological factors on social factors appears to be brought about 
through changes in subjective experience, the $\mathrm{B} \rightarrow \mathrm{S}$ pathway also appears to be mediated by psychological factors.

One can also hypothesize, however, that changes in biological factors (e.g., experiencing mobility limitations due to an accident, genetic defects, a chronic health condition, etc.) could influence social factors. For example, dependent on prevalent social norms, an individual may receive social support or rejection (if there is stigma attached to a health condition; Heijnders and Van Der Meij, 2006). Nonetheless, whether or not an individual would benefit or get harmed by such social influences (i.e., the health related influence) happens through $\mathrm{S} \rightarrow \mathrm{P}$ and $\mathrm{S} \rightarrow \mathrm{B}$ pathways described earlier.

\section{The significance of understanding subjective experience}

Engel's emphasis on an individual's lived experiences (Engel, 1980; Wade and Halligan, 2017) directly connects to subjective experience, which is an individual's experience from a first-person perspective. Subjective experience constitute psychological factors such as emotions, perceptions, preferences, goals, etc., that are relevant to that person's private world (i.e., inner experiences) at a given point in their lives, and represents an epistemologically and ontologically distinct domain of understanding (Beauregard, 2007; Karunamuni, 2015; Karunamuni and Weerasekera, 2019). Albert Bandura, a well-known cognitive psychologist emphasized that subjective experience and objective measures are governed by their own set of principles that must be studied in their own right (Bandura, 2001). With regards to the brain, neurologist Mario Beauregard refers to these two levels metaphorically as "mentalese" (the language of the mind) and "neuronese" (the language of the brain), and also describes how the two 
levels can influence one another since they are interdependent (Beauregard, 2007). This conceptualization is also in line with many who have highlighted the importance of avoiding reductionist strategies when it comes to understanding conscious minds (subjective experience) and objective biomedical data (Akram and Giordano, 2017; Clark, 2018; Davies and Roache, 2017).

Considering subjective experience, it is possible to conceive that various psychological factors relating to an individual can determine whether that individual will be influenced (i.e., if changes in various aspects of SWB would happen) as a result of a specific social or biological factor. For example, an individual's likes and dislikes (which relate to attitudes, perceptions, etc.) can determine whether an individual will be positively or negatively influenced (or even not influenced) by a given social factor such as a life event. Note that an individual's likes and dislikes directly connect to the concept of attachments that an individual holds towards various domains in life (such as towards significant others, to material possessions, life-goals, views and opinions, etc.) that can change during an individual's lifetime. Further, likes and dislikes can influence the generation of positive or negative affect following an experience (Karunamuni and Weerasekera, 2019).

Research findings demonstrate that different life events (such as relocation, birth of a child, retirement, divorce, etc.) can have very different effects on different individual's SWB (Diener et al., 2017b). Further, social policies appear to influence people differently based on individual's preferences, such as religious persons being happier in religious nations than nonreligious nations and vice versa (Diener et al., 2017b; Diener et al., 2018b), and parental leave policies specifically increasing parental 
SWB (Diener et al., 2017b). Even when considering social support, everyone may not benefit equally by having a large social network. Some people are socially isolated but are not lonely and similarly, some are lonely even if they have a lot of social contacts, demonstrating that it is the subjective experience of loneliness that is harmful, rather than the actual number of social contacts a person has (Miller, 2011). Other studies have found some individuals actively seek solitude and even thrive during solitude (Coplan and Bowker, 2013).

In terms of biological factors, the extent to which an individual would experience a change in various aspects of SWB (e.g., low positive affect and high negative affect) as a result of a physical health condition (i.e., the $\mathrm{B} \rightarrow \mathrm{P}$ pathway) can vary among individuals (Backe et al., 2018) depending on different psychosocial factors including an individual's previously conditioned preferences.

When considering subjective experience, individual differences also appear to be present in the psychological habit of rumination (Lyubomirsky et al., 2015; Wang et al., 2015), and ruminating tendencies could influence the extent to which any stressful event would negatively influence an individual. (The habit of rumination is explored further under the subsection "The BPS-Pathways model and its implications").

Based on what was presented above, it can also be inferred that the influence of social factors on biological factors (the $\mathrm{S} \rightarrow \mathrm{B}$ pathway) is mediated by psychological factors (when considering social factors as the predictor variable, biological factors as the criterion variable and psychological factors as the meditating variable). Experimental manipulations that have induced psychological stress provide further evidence for this mediation, where studies have consistently demonstrated the magnitude of change in 
biomarkers in an individual depends on psychological factors relevant to that individual, such as having a lower subjective social status (Derry et al., 2013), the presence of chronic interpersonal stress (Miller et al., 2009), whether or not the person engages in rumination (Gianferante et al., 2014), and an individual's social anxiety and rejection sensitivity (Maner et al., 2010). Additional evidence for this mediation come from cases where early childhood experiences predict physical health issues later on in life (discussed under the $\mathrm{S} \rightarrow \mathrm{B}$ pathway), where these changes also appear to be associated with individual level changes such as HPA axis changes, epigenetic changes, as well as structural changes in the brain (Bedrosian et al., 2018; Davidson and McEwen, 2012; McGowan et al., 2009), which are changes that result from experiencing psychological stress (described earlier when discussing the $\mathrm{P} \rightarrow \mathrm{B}$ pathway).

The mediating influence of psychological factors on the $\mathrm{S} \rightarrow \mathrm{B}$ pathway is also apparent when considering an individual's subjective experience. A social factor (i.e., a life event, an interpersonal experience, social policy, etc.) cannot affect or influence an individual unless that individual encounters that social factor within his/her subjective experience (i.e., information regarding a life event, etc., needs to enter via that individual's five senses to influence that individual; Karunamuni, 2015; Karunamuni and Weerasekera, 2019). Once the social factor is experienced and if the individual is vulnerable to that social factor (i.e., based on his/her likes and dislikes, ruminating tendencies, etc., as explained above), various emotions can get generated (the $S \rightarrow P$ pathway), and in turn bring about biological changes (such as HPA axis reactivity, increases in inflammatory markers, changes in neural circuits, etc., as discussed in the $\mathrm{P} \rightarrow \mathrm{B}$ pathway). 
Various social and sociocultural influences can constantly shape an individual's likes and dislikes. For example, as a result of sociocultural influences, there appears to be differences between individualist nations and collectivist nations in terms of the value people place on issues like objective social status (education) versus subjective social status, pursuing success and excitement in life versus achieving contentment and calm, as well as other factors such as situations that may predict work-related job satisfaction (Diener et al., 2017b; Diener et al., 2018b). As a result of this sociocultural influence, if an individual's cognitions or beliefs differ substantially from those prevalent around them, a person may experience diminished SWB (Diener et al., 2017b; Diener et al., 2018b). Research has demonstrated that psychological changes which result from sociocultural events also lead to structural changes in the brain (Park and Huang, 2010), as would be expected based on the literature on brain plasticity discussed earlier.

The mediation of psychological factors is also relevant to the $\mathrm{B} \rightarrow \mathrm{S}$ pathway (when considering biological factors as the predictor variable, social factors as the criterion variable and psychological factors as the meditating variable). When biological factors contribute to SWB (the B $\rightarrow$ P pathway), feelings of SWB may motivate an individual to be engaged in social involvements ( $\mathrm{P} \rightarrow \mathrm{S}$ pathway) that result in social influences, perhaps further promoting their SWB, as explained earlier. In contrast, experiencing physical illness could lower an individual's SWB and this may have an opposite effect on that individual's social involvements. Still, there can be individual differences based on a particular individual's likes and dislikes such as an individual preferring solitude even when he or she has a high SWB. 


\section{The BPS-Pathways model and its implications}

The above-discussed causal pathways among biological, psychological, and social factors are displayed in Figure 1, section (ii). The BPS-Pathways model (Figure 2) is based on these pathways. Four major pathways are displayed (in both of the above figures), namely $\mathrm{B} \rightarrow \mathrm{P}, \mathrm{P} \rightarrow \mathrm{B}, \mathrm{S} \rightarrow \mathrm{P}$ and $\mathrm{P} \rightarrow \mathrm{S}$ pathways. Based on the evidence we presented, the $\mathrm{S} \rightarrow \mathrm{B}$ pathway appears to be mediated by psychological factors (i.e., the $\mathrm{S} \rightarrow \mathrm{B}$ pathway constitutes $\mathrm{S} \rightarrow \mathrm{P}$ pathway followed by $\mathrm{P} \rightarrow \mathrm{B}$ pathway). Further, the health-related influence of the $\mathrm{B} \rightarrow \mathrm{S}$ pathway appears to happen through the $\mathrm{S} \rightarrow \mathrm{P}$ and $\mathrm{S} \rightarrow \mathrm{B}$ pathways, as discussed. Therefore, $\operatorname{direct} \mathrm{S} \rightarrow \mathrm{B}$ and $\mathrm{B} \rightarrow \mathrm{S}$ pathways (that are not mediated by psychological factors) are displayed in the two figures using gray dotted lines.

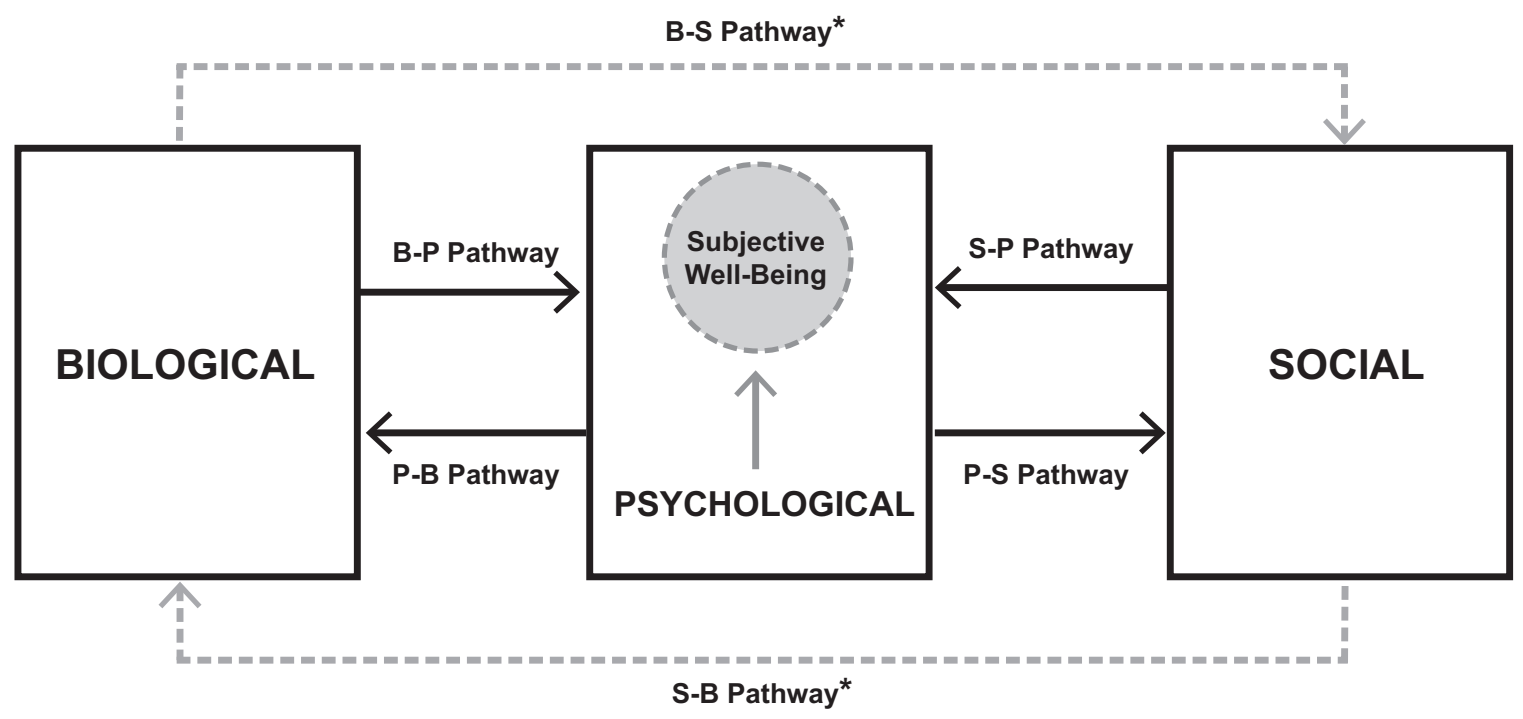

Fig 2. The BPS-Pathways model depicting the pathways among biological, psychological, and social factors.

* Direct $\mathrm{S} \rightarrow \mathrm{B}$ and $\mathrm{B} \rightarrow \mathrm{S}$ pathways (that are not mediated by psychological factors) are indicated by gray dotted lines. 
The three major criticisms of Engel's $(1977,1980)$ BPS model are that (1) it is too vaguely defined and therefore not testable, (2) it is too generic and cannot be efficiently put into practice, and (3) it does not include a method to identify relevant BPS data (Benning, 2015; Farre and Rapley, 2017; Ghaemi, 2010). By considering the pathways through which the BPS variables are causally linked, the current formulation addresses all three of these criticisms. In the BPS-Pathways model, the relationships among the variables are not only empirically testable, but these relationships already have a great deal of evidence that come from hundreds of currently existing studies. Note that several recent review articles that have established causal directions among BPS variables were cited in this article. (Additional reviews and epidemiological studies that further validate these causal directions as well as studies that have examined BPS-variables as determinants of illness and health are too numerous to list here.) Further, understanding the relationships among these variables within the BPS-Pathways framework can provide guidance to health professionals to assess, address and prioritize different entry points for intervention as well as tailor interventions based on a patient's vulnerability and care needs. Let us now consider some examples of how understanding of BPS-Pathways can be helpful for clinical decision-making, and when designing health promotion interventions.

The efficacy of vaccines has been found to be inconsistent across populations (Dowd et al., 2018; Li et al., 2015), and to overcome this issue, current research focuses on further developing innovative biotechnology tools (i.e., $\mathrm{B} \rightarrow \mathrm{B}$ pathways) that target host-pathogen interactions at the molecular level (Davenne and McShane, 2006). Yet, numerous studies not only indicate that stress, anxiety and depression compromise the 
immune system (Bonneau et al., 2007; Kiecolt-Glaser, 2009), but also that differences in efficacy of vaccines appear to happen due to social determinants and psychosocial stressors (Dowd et al., 2018; Phillips, 2011). Therefore, this situation calls for addressing the $\mathrm{P} \rightarrow \mathrm{B}$ pathway before addressing the $\mathrm{B} \rightarrow \mathrm{B}$ pathway that lead to SWB (through the $\mathrm{B} \rightarrow \mathrm{P}$ pathway), i.e., addressing psychosocial stresses (at least to some threshold level, which needs to be determined) before administering vaccines. This issue may be relevant for other types of biological interventions such as surgical recovery (Mavros et al., 2011).

As another example of the applicability of the BPS-Pathways model, we can consider functional somatic syndromes (sometimes referred to as "medically unexplained symptoms"), which is an important component of the global burden of disease that can diminish an individual's SWB (Henningsen et al., 2018). Here, patient's complaints of pain, weakness, and fatigue remain unexplained by identifiable disease even after extensive medical assessments (Henningsen et al., 2018). These syndromes also appear to be associated with adverse life events, traumatic childhood experiences, and stressful work conditions (Afari et al., 2014; Bonvanie et al., 2017; Henningsen et al., 2018), which could activate the $\mathrm{P} \rightarrow \mathrm{B}$ pathway (as described earlier). Although psychological interventions are often used for managing these syndromes (Henningsen et al., 2018), understanding these conditions within the causal framework of the BPS-Pathways model provides a rational basis for addressing factors such as ruminative tendencies (before such mental habits translate into observable biological changes through the $\mathrm{P} \rightarrow \mathrm{B}$ pathway).

As mentioned earlier, social influences can motivate an individual to engage in health enhancing or health harming behaviors, affecting biological factors (the $\mathrm{S} \rightarrow \mathrm{B}$ 
pathway mediated by psychological factors). In this regard, population-based strategies (the $\mathrm{P} \rightarrow \mathrm{S}$ pathway) that bring about changes in social norms and behaviors have the potential to increase SWB of the target group as well as objective physical health through the $S \rightarrow B$ pathway mediated by psychological factors. Indeed, research demonstrates that implementing interventions that alter knowledge, attitudes, and behaviors in population groups bring about changes in SWB (Glanz et al., 2008). As an example, a large longitudinal study that used messages about back pain improved population and general practitioner beliefs and behaviors, and reduced disability as well as workers' compensation costs related to back pain (Buchbinder et al., 2001). Further, when considering that the $S \rightarrow B$ pathway appears to be mediated by psychological factors, interventions that target psychological factors that are relevant to a group may have a higher intervention impact. For example, smoking prevention programs for adolescents appear to be more successful if they emphasize the immediate negative effects of smoking such as bad breath or unattractiveness rather than long-term effects such as higher mortality (Harvey and Chadi, 2016). Additionally, interventions targeting psychological factors can also prevent some types of negative social influences. For example, teaching children techniques to avoid peer pressures to engage in unhealthy behaviors (such as drug abuse) may prevent or reduce unhealthy social influences (Botvin and Griffin, 2007).

The BPS model is perhaps particularly relevant for the field of psychiatry, considering that psychiatry currently uncomfortably spans biological and psychosocial perspectives on mental illness (Davies and Roache, 2017). There also appear to be a "causality gap" in psychiatric neuroscience on how to connect neural circuit alterations in 
the brain with patient's subjective experience involving stories about their lives and struggles (Etkin, 2018). Therefore, let us explore how the BPS-Pathways model can inform the field of psychiatry.

The powerful $\mathrm{P} \rightarrow \mathrm{B}$ pathway backed by multiple independent lines of evidence support psychological interventions that can bring about changes in brain structures in favorable directions. Psychological interventions enable individuals to disclose thoughts and feelings, obtain information and resources to address practical difficulties in life as well as gain hope for recovery. Studies indicate that such interventions are efficacious even for individuals with serious mental illnesses (Lewis and Lewis, 2016; Olatunji et al., 2013; Werner, 2012). Following psychotherapy, research investigations have demonstrated favorable changes in objectively measurable biomarkers, epigenetic changes as well as favourable structural and functional changes in the brain (Boyd et al., 2018; Feinstein and Church, 2010; Stahl, 2012). Several investigations have also demonstrated that reductions in patient's psychological symptoms correlate with observed biological changes in the brain (Hölzel et al., 2010; Jacobs et al., 2016; Keshavan et al., 2017; Santarnecchi et al., 2014; Valk et al., 2017). Further, some types of integrative body-mind training appear to bring about measureable changes in neural pathways after only a few hours of training (Posner et al., 2014).

When a life event disrupts issues that are central to an individual's SWB, rumination can result, which leads to prolonged activation of the HPA axis, as mentioned earlier. Neuroimaging studies have also shown that rumination differentially activate various subsystems of the brain, especially the Default-Mode Network (DMN) (Whitfield-Gabrieli and Ford, 2012). This activation has been linked to worse cognitive 
performance as well as deficits in attention and working memory in healthy individuals (Whitfield-Gabrieli and Ford, 2012), and appears to be associated with several psychiatric conditions (Buckner et al., 2008; Whitfield-Gabrieli and Ford, 2012). Several studies also indicate that psychological interventions are capable of reducing rumination as well as reducing DMN activity (Garrison et al., 2015; Simon et al., 2017) and also that reductions in rumination result in significant improvements in psychiatric symptoms (Kaplan et al., 2018; Perestelo-Perez et al., 2017; Querstret and Cropley, 2013; van der Velden, 2015).

Even for the development of conditions like dementia, the $\mathrm{P} \rightarrow \mathrm{B}$ pathway may play a significant role, considering that large longitudinal studies show psychological stress and anxiety are significant risk factors for developing cognitive impairment and Alzheimer's disease later in life (Bisht et al., 2018; Escher et al., 2019; Gimson et al., 2018; Justice, 2018). Further, psychological interventions that tend to reduce stress appear to be beneficial for patients with dementia, capable of modifying the course of the disease (Larouche et al., 2015; Lima et al., 2019; Russell-Williams et al., 2018). Studies have also demonstrated that engaging in cognitive tasks reduce the activity of the DMN (Buckner et al., 2008; Raichle et al., 2001) and this may explain why engaging in intellectual activities appear to significantly lower the risk of dementia (Blacker and Weuve, 2018; Lee, 2018; Sajeev et al., 2016; Yates et al., 2016), as well as why educated individuals have a lower rate of dementia (Ngandu et al., 2007; Qiu et al., 2009). It is also interesting to note that trait mindfulness is strongly negatively correlated with rumination (Keng et al., 2011; Perestelo-Perez et al., 2017; Tomlinson et al., 2017) and the practice 
of meditation is capable of reducing the DMN activity beyond the typical reductions observed during cognitive tasks (Garrison et al., 2015; Simon et al., 2017).

Considering social factors applicable to psychiatry, interventions and social policies aimed at improving social circumstances and building local communities as well as preventing abuse can be effective interventions. For example, current research indicates that family therapy, that reduces relative's critical patterns of communication, is significantly beneficial for patients to recover from mental disorders (Cooke et al., 2014; Pitschel-Walz et al., 2001; Reinares et al., 2016). Further, considering that the S $\rightarrow$ B pathway is mediated through psychological factors, addressing psychological factors can be beneficial when social circumstances are difficult to change. A recent experimental study found that individuals' trait mindfulness predicted less distress following a social rejection incident (Martelli et al., 2018). Other studies also indicate that mindfulness training may buffer social distress (Keng et al., 2013; Lindsay et al., 2019; Roemer et al., 2015).

Another consideration of a social factor relevant to psychiatry comes from evidence that diagnostic labels assigned for mental health issues (based on the Diagnostic and Statistical Manual of Mental Disorders; American Psychiatric Association, 2013) may generate social stigma and disempower individuals (Cooke et al., 2014; Perkins et al., 2018). Here, it is conceivable this situation has the potential to activate the $S \rightarrow P$ pathway as well as the $\mathrm{P} \rightarrow \mathrm{B}$ pathway.

In terms of biological factors relevant for psychiatry, potential risk genes for mental disorders appear to number in the hundreds, but each contributes only a small percentage to overall risk (Bogdan et al., 2018; Border et al., 2019; Dubovsky, 2016; 
Zubenko et al., 2018; Zwicker, 2017). Further, studies that have investigated case-control differences between various types of major psychiatric disorders have consistently observed transdiagnostic overlap across disorders (Elliott et al., 2018; Pinto et al., 2017; Sprooten et al., 2018). It is also interesting to note that rumination has been identified as a transdiagnostic process, defined as a mechanism that causally contributes to the onset, maintenance, or recurrence of multiple psychiatric disorders (Kaplan et al., 2018; Watkins, 2015). Further, even in mental disorders that may have a strong genetic contribution (such as autism; Sandin et al., 2017), studies indicate that psychological interventions reduce symptoms and also bring about changes in the structure of the brain that correlate with improved psychological and behavioral functioning (Stavropoulos, 2017; Van Hecke et al., 2015; Yang et al., 2018). Additionally, early life trauma induced alterations in affective and stress responses have been observed to reverse through psychological interventions (Bethell et al., 2016; Koe et al., 2016; Ortiz and Sibinga, 2017). Also, the benefits of psychiatric drugs may be overestimated while their toxicity is underestimated (Adlington, 2018; Hengartner et al., 2018; Wand, 2019).

As another example of the applicability of the BPS-pathways model, we can consider how this model can be used to address sleep disorders. During sleep, widespread biological and physiological changes occur throughout the body, and therefore the absence of sleep can have serious health consequences, adversely affecting SWB (Medic et al., 2017). Stressful life events, worries and anxieties along with the habit of rumination (that also leads to the continuous activation of the HPA axis) appear to significantly contribute to sleep problems (Dregan et al., 2013; Hirotsu et al., 2015; Santarnecchi et al., 2018). Further, worrying about the lack of sleep (known as "insomnia 
identity") itself has also been found to be a better predictor of poor health than sleep that is measured (Lichstein, 2017). All this research points to the importance of psychological interventions for sleep disorders. In terms of biological interventions, although sleep medications for a short duration maybe warranted for some patients (Limandri, 2018), these medications are known to have significant side effects (Limandri, 2018) that can adversely contribute to SWB. It is also interesting to note that there appears to be differences in DMN connectivity patterns associated with sleep-related problems (Santarnecchi et al., 2018; Tashjian et al., 2018; Ward et al., 2013). As stated earlier, rumination is also associated with differences in DMN connectivity patterns (WhitfieldGabrieli and Ford, 2012; Zhu et al., 2017) and further, psychological interventions that are capable of addressing sleep disorders (e.g., cognitive behavioural therapy and mindfulness meditation) appear to bring about measurable changes in DMN connectivity patterns (Simon and Engström, 2015; Taylor et al., 2013). Therefore, investigating these changes in terms of affected brain regions as well as the direction of change could inform future intervention efforts aimed at a functional recovery of patients suffering from sleep disorders.

Regarding SWB, it should be noted that all the pathways to SWB discussed thus far in this article focused on increasing hedonic well-being (Dambrun and Ricard, 2011; Wallace and Shapiro, 2006), which relates to experiencing pleasant stimuli and avoiding unpleasant stimuli (for example, the experience of psychological stress and the alleviation of stress). A very different type of well-being is eudaimonic well-being, which is described as a durable form of happiness that is not dependent on circumstances, and involve inner peace, wisdom, and contentment (Dambrun et al., 2012; Karunamuni and 
Weerasekera, 2019; Ryan and Deci, 2001). Studies indicate that eudaimonic well-being is also associated with spirituality, and significantly contribute to favorable changes in physiological markers of health (Dambrun et al., 2012; Moons et al., 2019; Ryff, 2018) thereby uniquely contributing to SWB. It can also be noted here that individuals who are high in eudaimonic wellbeing may display greater resilience towards negative impacts of physical health problems and social challenges in life (Moons et al., 2019). Thus, spirituality can be considered to be another important $\mathrm{P} \rightarrow \mathrm{B}$ pathway that has the potential to be addressed in patient care (Park et al., 2017). [Note that spirituality as well as religiosity are terms that are generally considered to be challenging to uniquely define (Park et al., 2017; Saad et al., 2017). Nonetheless, several researchers think the biopsychosocial model needs to include the spiritual dimension (Park et al., 2017; Saad et al., 2017).]

It should be acknowledged that various authors have developed disease specific models that take into account various BPS factors (Hunt et al., 2008; Pietromonaco and Collins, 2017; Wood et al., 2015). Although different BPS-pathways maybe more relevant for specific health conditions, we think the causal directions portrayed in the BPS-Pathways model can be helpful in conceptualizing and developing disease specific models. Based on the BPS-Pathways model, the influential pathways that lead to various aspects of SWB are $\mathrm{S} \rightarrow \mathrm{P}$ and $\mathrm{B} \rightarrow \mathrm{P}$ pathways, and as discussed, these influences can be impacted by psychological factors that differ among individuals (e.g., likes and dislikes, ruminating tendencies, aspects of eudaimonic wellbeing). For objective health outcomes, the influence of $\mathrm{P} \rightarrow \mathrm{B}$ and $\mathrm{S} \rightarrow \mathrm{B}$ pathways (the latter mediated by psychological factors) appear to be important. It would also be helpful for disease specific models to take into 
consideration $\mathrm{B} \rightarrow \mathrm{B}, \mathrm{P} \rightarrow \mathrm{P}$ and $\mathrm{S} \rightarrow \mathrm{S}$ pathways that are unique to a particular health condition.

\section{Strengths, limitations and future directions for the BPS-Pathways model}

There have been recent publications that present relationships among biopsychosocial variables (Bolton and Gillett, 2019; Haslam et al., 2019). The BPSPathways model improves upon these, considering that it does not give priority to any of the three BPS variables, but considers them as distinct 'systems' (which can be conceptually separated, defined and measured), capable of causally influencing each other and contributing to outcome health measures — this approach increases the applicability of the model and additionally avoids contentious assumptions such as the need to reject or promote materialist-dualist thought frameworks.

Another strength of the BPS-Pathways model is that it can be adopted for any health condition. As discussed in the article, although the two outcome variables (SWB and physical health) can influence each other, specifying an outcome variable maybe more appropriate when developing a BPS model for a given health condition. The interrelationships presented in the BPS-Pathways model can also be helpful to sieve through and organize the complex web of causal factors for a given disease condition and can even be utilized in simulation modeling, which are mathematical models that can be used to predict health outcomes.

The determination that a given association is causal is important since this information can indicate the possibility for intervention to improve health outcomes (Glass et al., 2013; Chiolero, 2018). If we briefly consider here epidemiological criteria 
that are typically used to establish causality, the presence of a 'temporal relationship' (a criterion that is sometimes described as the only factor needed to establish causality between variables; Glass et al., 2013) is evident in all of the pathways we discussed. [Note: The field of epidemiology originally emerged to explain causation of epidemic diseases. However, epidemiological criteria are now widely applied in different fields of study (Tyler and Last, 1991). The updated criteria used to establish causation are: temporal relationship, strength of the association, dose-response relationship, replication of the findings, biological plausibility, consideration of alternative explanations, cessation of exposure, specificity of the association and consistency with other knowledge (Gordis, 2000).] Although it is beyond the scope of this article to explore the applicability of other criteria in detail (and some criteria may not be directly relevant in our current context), criteria such as the 'strength of the association,' 'dose-response relationship,' 'replication of the findings,' and 'cessation of exposure' is also evident in the pathways presented.

One challenge in using the BPS-Pathways model can be the necessity to accurately classify factors into biological, psychological, and social variables for a given health condition. For example, in this article, we considered factors that can impact the physical body (such as the availability of food/water, toxic exposures, and access to medical care/insurance) as factors that can directly impact objective health through the $\mathrm{B} \rightarrow \mathrm{B}$ pathway and consequently influence SWB through the $\mathrm{B} \rightarrow \mathrm{P}$ pathway. Others, however, may regard these influences as 'social factors' that contribute perhaps to a direct $S \rightarrow B$ pathway. An advantage in the approach we used is that it enables one to understand an unfavorable social situation (such as poverty) both as material deprivation that can influence physical health through the B $\rightarrow$ B pathway (and then influence SWB 
through the $\mathrm{B} \rightarrow \mathrm{P}$ pathway), as well as though the $\mathrm{S} \rightarrow \mathrm{B}$ pathway (i.e., mediated by psychological factors, such as feelings of deprivation or stress). Similarly, a disease like asthma [for which both environmental toxins prevalent in impoverished neighborhoods as well as psychosocial stressors appear to play a role (Wood et al., 2015)] can be understood through $\mathrm{B} \rightarrow \mathrm{B}$ pathways as well as through the $\mathrm{P} \rightarrow \mathrm{B}$ and $\mathrm{S} \rightarrow \mathrm{B}$ pathways, where the latter is mediated by psychological factors.

Although there is a substantial amount of evidence spanning many decades of research supporting the BPS-Pathways presented, another limitation of the model is that it is based on the specific BPS factors that have been investigated and reviewed by the articles we examined (i.e., the article did not examine every potential BPS factor that could influence each other). Future research could provide additional evidence supporting BPS causal pathways and investigate the magnitude of effect sizes of these pathways. These investigations can also explore different variables representing BPS factors and different measures of outcome variables for specific health conditions as well as for different stages of specific health conditions. Analyses can also be conducted to further understand the mediation role of psychological factors.

\section{Summary and Conclusions}

The currently popular biopsychosocial model takes into consideration biological, psychological, and social factors that can contribute to health and illness. While a great deal of literature exists on how psychological, social, and biological factors are separately associated with health and illness, causal links among these factors have not been elucidated. In this article, we described that biological, psychological, and social factors 
can be considered as distinct 'systems' that can be conceptually separated, defined, and measured; we also depicted how interrelationships among these factors can be investigated. We employed analytical reasoning and examined research evidence to present an updated theoretical model: the BPS-Pathways model (Figure 2). We discussed all six potential pathways that can happen among biological, psychological, and social factors as well as how they can potentially contribute to subjective well-being and to objective physical health outcomes. According to this model, the influential pathways that lead to subjective well-being are $\mathrm{S} \rightarrow \mathrm{P}$ and $\mathrm{B} \rightarrow \mathrm{P}$ pathways, although as discussed, these pathways can be impacted by psychological factors that differ among individuals. For objective health outcomes, the $\mathrm{P} \rightarrow \mathrm{B}$ and $\mathrm{S} \rightarrow \mathrm{B}$ pathways appear to be important where the latter pathway is mediated by psychological factors.

In this article, we also highlighted the significance of systematically understanding subjective experience, which represents an epistemologically distinct domain. Further, we described that the mental habit of rumination (which results in the continual activation of the hypothalamus-pituitary-adrenal axis) has been characterized as a transdiagnostic process that can causally contribute to a host of mental as well as physical health problems, and also that rumination is amenable to psychological interventions.

The BPS-Pathways model presents an overarching framework that can have important implications for clinical practice as well as for research and can be useful for tailoring personalized medicine. 


\section{References}

Acabchuk, R. L., Kamath, J., Salamone, J. D., \& Johnson, B. T. (2017). Stress and chronic illness: The inflammatory pathway. Social Science \& Medicine, 185, 166-170.

Adlington, K. (2018). Pop a million happy pills? Antidepressants, nuance, and the media. BMJ: British Medical Journal (Online), 360.

Afari, N., Ahumada, S.M., Wright, L.J., Mostoufi, S., Golnari, G., Reis, V., et al. (2014). Psychological trauma and functional somatic syndromes: a systematic review and metaanalysis. Psychosomatic Medicine, 76, 2-11.

Akram, F., \& Giordano, J. (2017). Research Domain Criteria as Psychiatric Nosology: Conceptual, Practical and Neuroethical Implications. Cambridge Quarterly of Healthcare Ethics, 26(4), 592-601.

Alwis, D. S., \& Rajan, R. (2014). Environmental enrichment and the sensory brain: the role of enrichment in remediating brain injury. Frontiers in Systems Neuroscience, 8, 156.

American Psychiatric Association. (2013). Diagnostic and statistical manual of mental disorders (5th ed.). Washington, DC.

Ashar, Y. K., Chang, L. J., \& Wager, T. D. (2017). Brain mechanisms of the placebo effect: an affective appraisal account. Annual Review of Clinical Psychology, 13, 73-98.

Backe, I. F., Patil, G. G., Nes, R. B., \& Clench-Aas, J. (2018). The relationship between physical functional limitations, and psychological distress: Considering a possible mediating role of pain, social support and sense of mastery. SSM-population health, 4, 153-163.

Bandura, A. (1986). Social foundations of thought and action: A social cognitive theory. Englewood Cliffs, N.J.: Prentice Hall.

Bandura, A. (2001). Social cognitive theory: an agentic perspective. Annual Review of Psychology, 52, 1-26.

Bauer, U. E., Briss, P. A., Goodman, R. A., \& Bowman, B. A. (2014). Prevention of chronic disease in the 21 st century: elimination of the leading preventable causes of premature death and disability in the USA. The Lancet, 384 (9937), 45-52.

Beauregard, M. (2007). Mind does really matter: Evidence from neuroimaging studies of emotional self-regulation, psychotherapy, and placebo effect. Progress in Neurobiology, 81(4), 218-236. 
Bedrosian, T. A., Quayle, C., Novaresi, N., \& Gage, F. H. (2018). Early life experience drives structural variation of neural genomes in mice. Science, 359(6382), 1395-1399.

Bender, C. L., Calfa, G. D., \& Molina, V. A. (2016). Astrocyte plasticity induced by emotional stress: A new partner in psychiatric physiopathology?. Progress in NeuroPsychopharmacology and Biological Psychiatry, 65, 68-77.

Benning, T. B. (2015). Limitations of the biopsychosocial model in psychiatry. Advances in Medical Education and Practice, 6, 347.

Bethell, C., Gombojav, N., Solloway, M., \& Wissow, L. (2016). Adverse childhood experiences, resilience and mindfulness-based approaches: common denominator issues for children with emotional, mental, or behavioral problems. Child and Adolescent Psychiatric Clinics, 25(2), 139-156.

Bisht, K., Sharma, K., \& Tremblay, M. È. (2018). Chronic stress as a risk factor for Alzheimer's disease: roles of microglia-mediated synaptic remodeling, inflammation, and oxidative stress. Neurobiology of stress, 9, 9-21.

Black, D. S., \& Slavich, G. M. (2016). Mindfulness meditation and the immune system: a systematic review of randomized controlled trials. Annals of the New York Academy of Sciences, 1373(1), 13-24.

Blacker, D., \& Weuve, J. (2018). Brain Exercise and Brain Outcomes: Does Cognitive Activity Really Work to Maintain Your Brain?. JAMA psychiatry, 75(7), 703-704.

Bogdan, R., Baranger, D. A., \& Agrawal, A. (2018). Polygenic risk scores in clinical psychology: bridging genomic risk to individual differences. Annual Review of Clinical Psychology, 14, 119-157.

Bolton, D., \& Gillett, G. (2019). The biopsychosocial model of health and disease. Cham: Palgrave Pivot.

Bonneau, R. H., Padgett, D. A., \& Sheridan, J. F. (2007). Twenty years of psychoneuroimmunology and viral infections in Brain, Behavior, and Immunity. Brain, Behavior, and Immunity, 21(3), 273-280.

Bonvanie, I. J., Janssens, K. A., Rosmalen, J. G., \& Oldehinkel, A. J. (2017). Life events and functional somatic symptoms: a population study in older adolescents. British Journal of Psychology, 108(2), 318-333.

Border, R., Johnson, E. C., Evans, L. M., Smolen, A., Berley, N., Sullivan, P. F. et al. (2019). No support for historical candidate gene or candidate gene-by-interaction hypotheses for major depression across multiple large samples. American Journal of Psychiatry, 176(5), 376-387. 
Bottaccioli, A. G., Bottaccioli, F., \& Minelli, A. (2019). Stress and the psyche-brainimmune network in psychiatric diseases based on psychoneuroendocrineimmunology: a concise review. Annals of the New York Academy of Sciences, 1437(1), 31-42.

Botvin, G. J., \& Griffin, K. W. (2007). School-based programmes to prevent alcohol, tobacco and other drug use. International Review of Psychiatry, 19(6), 607-615.

Boyd, J. E., Lanius, R. A., \& McKinnon, M. C. (2018). Mindfulness-based treatments for posttraumatic stress disorder: a review of the treatment literature and neurobiological evidence. Journal of Psychiatry \& Neuroscience, 43(1), 7.

Buchbinder, R., Jolley, D., \& Wyatt, M. (2001). Population based intervention to change back pain beliefs and disability: three part evaluation. Bmj, 322(7301), 1516-1520.

Buckner, R.L., et al. (2008). The brain's default network: anatomy, function, and relevance to disease. Annals of the New York Academy of Sciences, 1124, 1-38.

Busch, L. Y., Pössel, P., \& Valentine, J. C. (2017). Meta-analyses of cardiovascular reactivity to rumination: A possible mechanism linking depression and hostility to cardiovascular disease. Psychological Bulletin, 143(12), 1378.

Chen, X. (2015). Relative deprivation and individual well-being: Low status and a feeling of relative deprivation are detrimental to health and happiness. IZA world of labor: evidence-based policy making, 2015.

Chiolero, A. (2018). Data Are Not Enough-Hurray For Causality!, American Journal of Public Health, 108, 622-622.

Clark, J. (2018). Where neuroscience and education meet: Can emergentism successfully occupy the middle ground between mind and body?. Educational Philosophy and Theory, 50(4), 404-416.

Cole, S. W. (2013). Social regulation of human gene expression: mechanisms and implications for public health. American Journal of Public Health, 103(S1), S84-S92.

Coplan, R. J., \& Bowker, J. C. (Eds.). (2013). The handbook of solitude: Psychological perspectives on social isolation, social withdrawal, and being alone. John Wiley \& Sons.

Cooke, A., Basset, T., Bentall, R., Boyle, M., Cupitt, C., \& Dillon, J. (2014).

Understanding psychosis and schizophrenia. London: British Psychological Society.

Corlett, P.R., \& Marrouch, N. (2018). Social Cognitive Neuroscience of Attitudes and Beliefs, in the Handbook of Attitudes, Volume 1: Basic Principles (Routledge). 
Cross, M. P., Hofschneider, L., Grimm, M., \& Pressman, S. D. (2018). Subjective wellbeing and physical health. In E. Diener, S. Oishi, \& L. Tay (Eds.), Handbook of wellbeing. Salt Lake City.

Dambrun, M., \& Ricard, M. (2011). Self-centeredness and selflessness: A theory of selfbased psychological functioning and its consequences for happiness. Review of General Psychology, 15(2), 138-157.

Dambrun, M., Ricard, M., Després, G., Drelon, E., Gibelin, E., Gibelin, M., et al. (2012). Measuring happiness: From fluctuating happiness to authentic-durable happiness.

Frontiers in Psychology, 3, 16.

Davenne, T., \& McShane, H. (2016). Why don't we have an effective tuberculosis vaccine yet?. Expert Review of Vaccines, 15(8), 1009-1013.

Davidson, R. J., \& McEwen, B. S. (2012). Social influences on neuroplasticity: stress and interventions to promote well-being. Nature Neuroscience, 15(5), 689.

Davies, W., \& Roache, R. (2017). Reassessing biopsychosocial psychiatry. The British Journal of Psychiatry, 210(1), 3-5.

De Neve, J. E., Diener, E., Tay, L., \& Xuereb, C. (2013). The objective benefits of subjective well-being. In J. Helliwell, R. Layard, \& J. Sachs (Eds.), World happiness report 2013 (pp. 54-79). New York, NY: UN Sustainable Development Solutions Network.

Derry, H. M., Fagundes, C. P., Andridge, R., Glaser, R., Malarkey, W. B., \& KiecoltGlaser, J. K. (2013). Lower subjective social status exaggerates interleukin-6 responses to a laboratory stressor. Psychoneuroendocrinology, 38(11), 2676-2685.

Diener, E., Pressman, S. D., Hunter, J., \& Delgadillo-Chase, D. (2017a). If, why, and when subjective well-being influences health, and future needed research. Applied Psychology: Health and Well-Being, 9(2), 133-167.

Diener, E., Heintzelman, S. J., Kushlev, K., Tay, L., Wirtz, D., Lutes, L. D., et al. (2017b). Findings all psychologists should know from the new science on subjective well-being. Canadian Psychology, 58(2), 87.

Diener, E., Lucas, R. E., \& Oishi, S. (2018a). Advances and open questions in the science of subjective well-being. Collabra. Psychology, 4(1).

Diener, E., Oishi, S., \& Tay, L. (2018b). Advances in subjective well-being research. Nature Human Behaviour, 1.

Dowd, J. B., Fletcher, H. A., \& Boccia, D. (2018). Social determinants and BCG efficacy: a call for a socio-biological approach to TB prevention. F1000Research, 7. 
Dregan, A., Lallukka, T., \& Armstrong, D. (2013). Potential pathways from biopsychosocial risk factors to sleep loss due to worry: a population-based investigation. Journal of Public Mental Health, 12(1), 43-50.

Dubovsky, S. L. (2016). The limitations of genetic testing in psychiatry. Psychotherapy and Psychosomatics, 85(3), 129-135.

Elliott, M. L., Romer, A., Knodt, A. R., \& Hariri, A. R. (2018). A connectome-wide functional signature of transdiagnostic risk for mental illness. Biological psychiatry, 84(6), 452-459.

Engel, G. L. (1977). The need for a new medical model: a challenge for biomedicine Science, 196(4286), 129-136.

Engel, G. L. (1980). The clinical application of the biopsychosocial model. American journal of Psychiatry, 137, 535-544.

Escher, C. M., Sannemann, L., \& Jessen, F. (2019). Stress and Alzheimer's disease. Journal of Neural Transmission, 1-7.

Etkin, A. (2018). Addressing the causality gap in human psychiatric neuroscience. JAMA psychiatry, 75(1), 3-4.

Evers, A. W., Colloca, L., Blease, C., Annoni, M., Atlas, L. Y., Benedetti, F., et al. (2018). Implications of placebo and nocebo effects for clinical practice: expert consensus. Psychotherapy and psychosomatics, 87(4), 204-210.

Farre, A., \& Rapley, T. (2017). The New Old (and Old New) Medical Model: Four Decades Navigating the Biomedical and Psychosocial Understandings of Health and Illness, Healthcare 5(4), 88.

Feinstein, D. \& Church, D. (2010). Modulating Gene Expression through Psychotherapy: The Contribution of Noninvasive Somatic Interventions. Review of General Psychology. 14 (4), 283-295.

Finn, S., \& Fancourt, D. (2018). The biological impact of listening to music in clinical and nonclinical settings: a systematic review. In Progress in Brain Research, 237, 173200.

Fuchs, E. \& Flügge, G. (2014). Adult neuroplasticity: more than 40 years of research research. Neural Plasticity, ID 541870.

Fuller, J. (2017). The new medical model: a renewed challenge for biomedicine. Canadian Medical Association Journal, 189, E640. 
Gianferante, D., Thoma, M. V., Hanlin, L., Chen, X., Breines, J. G., Zoccola, P. M., \& Rohleder, N. (2014). Post-stress rumination predicts HPA axis responses to repeated acute stress. Psychoneuroendocrinology, 49, 244-252.

Gimson, A., Schlosser, M., Huntley, J. D., \& Marchant, N. L. (2018). Support for midlife anxiety diagnosis as an independent risk factor for dementia: a systematic review. BMJ open, 8(4), e019399.

Garrison, K. A., Zeffiro, T. A., Scheinost, D., Constable, R. T., \& Brewer, J. A. (2015). Meditation leads to reduced default mode network activity beyond an active task. Cognitive, Affective, \& Behavioral Neuroscience, 15(3), 712-720.

Ghaemi, S.N. (2010). The Rise and Fall of the Biopsychosocial Model: Reconciling Art and Science in Psychiatry; Johns Hopkins University Press: Baltimore, MD, USA, ISBN 978-0-8018-9390-2.

Glanz, K., Rimer, B. K., \& Viswanath, K. (Eds.). (2008). Health Behavior and Health Education: Theory, Research, and Practice. John Wiley \& Sons.

Glass, T. A., Goodman, S. N., Hernán, M. A., \& Samet, J. M. (2013). Causal inference in public health. Annual Review of Public Health, 34, 61-75.

Gordis, L. (2000). Epidemiology (Philadelphia: W.B. Saunders, Chapter 13).

Gray, J. D., Kogan, J. F., Marrocco, J., \& McEwen, B. S. (2017). Genomic and epigenomic mechanisms of glucocorticoids in the brain. Nature Reviews Endocrinology, 13(11), 661.

Grierson, A. B., Hickie, I. B., Naismith, S. L., \& Scott, J. (2016). The role of rumination in illness trajectories in youth: linking trans-diagnostic processes with clinical staging models. Psychological Medicine, 46(12), 2467-2484.

Hänsel, A., Hong, S., Camara, R. J., \& Von Kaenel, R. (2010). Inflammation as a psychophysiological biomarker in chronic psychosocial stress. Neuroscience \& Biobehavioral Reviews, 35(1), 115-121.

Harvey, J., \& Chadi, N., Canadian Paediatric Society, \& Adolescent Health Committee. (2016). Preventing smoking in children and adolescents: Recommendations for practice and policy. Paediatrics \& Child Health, 21(4), 209-214.

Haslam, S. A., Haslam, C., Jetten, J., Cruwys, T., \& Bentley, S. (2019). Group life shapes the psychology and biology of health: The case for a sociopsychobio model. Social and Personality Psychology Compass, 13(8), 1-16. 
Heijnders, M., \& Van Der Meij, S. (2006). The fight against stigma: an overview of stigma-reduction strategies and interventions. Psychology, health \& medicine, 11(3), 353363.

Hengartner, M. P., Angst, J., \& Rössler, W. (2018). Antidepressant Use Prospectively Relates to a Poorer Long-Term Outcome of Depression: Results from a Prospective Community Cohort Study over 30 Years. Psychotherapy and Psychosomatics.

Henningsen, P., Zipfel, S., Sattel, H., \& Creed, F. (2018). Management of functional somatic syndromes and bodily distress. Psychotherapy and Psychosomatics, 87(1), 1231.

Hirotsu, C., Tufik, S., \& Andersen, M. L. (2015). Interactions between sleep, stress, and metabolism: From physiological to pathological conditions. Sleep Science, 8(3), 143-152.

Hölzel, B. K., Carmody, J., Evans, K. C., Hoge, E. A., Dusek, J. A., Morgan, L., et al. (2009). Stress reduction correlates with structural changes in the amygdala. Social Cognitive and Affective Neuroscience, 5(1), 11-17.

Hostinar, C. E. (2015). Recent developments in the study of social relationships, stress responses, and physical health. Current Opinion in Psychology, 5, 90-95.

Househam, A. M., Peterson, C. T., Mills, P. J., \& Chopra, D. (2017). The effects of stress and meditation on the immune system, human microbiota, and epigenetics. Advances in Mind-Body Medicine, 31(4), 10-25.

Howell, R. T., Kern, M. L., \& Lyubomirsky, S. (2007). Health benefits: Metaanalytically determining the impact of well-being on objective health outcomes. Health Psychology Review, 1(1), 83-136.

Hulett, J. M., \& Armer, J. M. (2016). A systematic review of spiritually based interventions and psychoneuroimmunological outcomes in breast cancer survivorship. Integrative Cancer Therapies, 15(4), 405-423.

Hunt, M. A., Birmingham, T. B., Skarakis-Doyle, E., \& Vandervoort, A. A. (2008). Towards a biopsychosocial framework of osteoarthritis of the knee. Disability and Rehabilitation, 30(1), 54-61.

Idler, E. L., \& Kasl, S. (1991). Health perceptions and survival: Do global evaluations of health status really predict mortality? Journal of Gerontology, 2 , S55-S65.

Jacobs, R. H., Watkins, E. R., Peters, A. T., Feldhaus, C. G., Barba, A., Carbray, J., et al. (2016). Targeting ruminative thinking in adolescents at risk for depressive relapse:

Rumination-focused cognitive behavior therapy in a pilot randomized controlled trial with resting state fMRI. PloS one, 11(11), e0163952. 
Johnson, B.T., Acabchuk, R.L., 2018. What are the keys to a longer, happier life?

Answers from five decades of health psychology research. Soc. Sci. Med. 196, 218-226.

Justice, N. J. (2018). The relationship between stress and Alzheimer's disease.

Neurobiology of stress, 8, 127-133.

Kanherkar, R. R., Stair, S. E., Bhatia-Dey, N., Mills, P. J., Chopra, D., \& Csoka, A. B. (2017). Epigenetic mechanisms of integrative medicine. Evidence-Based Complementary and Alternative Medicine, 2017.

Kaplan, D. M., Palitsky, R., Carey, A. L., Crane, T. E., Havens, C. M., Medrano, M. R., et al. (2018). Maladaptive repetitive thought as a transdiagnostic phenomenon and treatment target: An integrative review. Journal of Clinical Psychology.

Karunamuni, N. (2015). The Five-Aggregate Model of the Mind. SAGE Open, 5(2).

Karunamuni, N., and Weerasekera, R. (2019). Theoretical Foundations to Guide Mindfulness Meditation: A Path to Wisdom. Current Psychology, 38(3), 627-646.

Kashima, Y., Bain, P. G., \& Perfors, A. (2019). The Psychology of Cultural Dynamics: What Is It, What Do We Know, and What Is Yet to Be Known?. Annual Review of Psychology, 70, 499-529.

Kelly, S. J., \& Ismail, M. (2015). Stress and type 2 diabetes: a review of how stress contributes to the development of type 2 diabetes. Annual Review of Public Health, 36 , $441-462$.

Keng, S. L., Smoski, M. J., \& Robins, C. J. (2011). Effects of mindfulness on psychological health: a review of empirical studies. Clinical Psychology Review, 31(6), 1041-1056.

Keng, S.L., Robins, C.J., Smoski, M.J., Dagenbach, J., \& Leary, M.R. (2013).

Reappraisal and mindfulness: a comparison of subjective effects and cognitive costs. Behaviour Research and Therapy, 51(12), 899-904.

Keshavan, M. S., Eack, S. M., Prasad, K. M., Haller, C. S., \& Cho, R. Y. (2017). Longitudinal functional brain imaging study in early course schizophrenia before and after cognitive enhancement therapy. Neuroimage, 151, 55-64.

Kessler, R. C., McLaughlin, K. A., Green, J. G., Gruber, M. J., Sampson, N. A., Zaslavsky, A. M., et al. (2010). Childhood adversities and adult psychopathology in the WHO World Mental Health Surveys. The British Journal of Psychiatry, 197(5), 378-385.

Kiecolt-Glaser, J. K. (2009). Psychoneuroimmunology: Psychology's gateway to the biomedical future. Perspectives on Psychological Science, 4(4), 367-369. 
Koe, A. S., Ashokan, A., \& Mitra, R. (2016). Short environmental enrichment in adulthood reverses anxiety and basolateral amygdala hypertrophy induced by maternal separation. Translational Psychiatry, 6(2), e729.

Kristensen, T. D., Mandl, R. C., Jepsen, J. R., Rostrup, E., Glenthøj, L. B., Nordentoft, M., et al. (2018). Non-pharmacological modulation of cerebral white matter organization: A systematic review of non-psychiatric and psychiatric studies. Neuroscience \& Biobehavioral Reviews, 88, 84-97.

Kumar, V., A.K. Abbas \& J.C. Aster. 2015. Robbins \& Cotran Pathologic Basis of Disease, WB Saunders.

Larouche, E., Hudon, C., \& Goulet, S. (2015). Potential benefits of mindfulness-based interventions in mild cognitive impairment and Alzheimer's disease: an interdisciplinary perspective. Behavioural Brain Research, 276, 199-212.

Law, K. C., \& Tucker, R. P. (2018). Repetitive negative thinking and suicide: a burgeoning literature with need for further exploration. Current Opinion in Psychology, 22, 68-72.

Lee, A. T., Richards, M., Chan, W. C., Chiu, H. F., Lee, R. S., \& Lam, L. C. (2018). Association of daily intellectual activities with lower risk of incident dementia among older Chinese adults. JAMA psychiatry, 75(7), 697-703.

Lehman, B. J., David, D. M., \& Gruber, J. A. (2017). Rethinking the biopsychosocial model of health: understanding health as a dynamic system. Social and Personality Psychology Compass, 11(8), e12328.

Levy, B. R., Ferrucci, L., Zonderman, A. B., Slade, M. D., Troncoso, J., \& Resnick, S. M. (2016). A culture-brain link: Negative age stereotypes predict Alzheimer's disease biomarkers. Psychology and Aging, 31(1), 82.

Lewandowsky, S., Cook, J., Fay, N., \& Gignac, G. E. (2019). Science by social media: Attitudes towards climate change are mediated by perceived social consensus. Memory \& cognition, 1-12.

Lewis, G., \& Lewis, G. (2016). No evidence that CBT is less effective than antidepressants in moderate to severe depression. Evidence-Based Mental Health, 19(4), 125.

Li, S., Plebanski, M., Smooker, P., \& Gowans, E. J. (2015). Why Vaccines to HIV, HCV, and Malaria Have So Far Failed - Challenges to Developing Vaccines Against Immunoregulating Pathogens. Frontiers in Microbiology, 6, 1318.

Lichstein, K. L. (2017). Insomnia identity. Behaviour Research and Therapy, 97, 230241. 
Lima, S., Garrett, C., Machado, J. C., Vilaça, M., \& Pereira, M. G. (2019). Quality of life in patients with mild Alzheimer disease: the mediator role of mindfulness and spirituality. Aging \& mental health, 1-8.

Limandri, B. J. (2018). Insomnia: Will Medication Bring Rest?. Journal of Psychosocial Nursing and Mental Health Services, 56(7), 9-14.

Lindsay, E. K., Young, S., Brown, K. W., Smyth, J. M., \& Creswell, J. D. (2019).

Mindfulness training reduces loneliness and increases social contact in a randomized controlled trial. Proceedings of the National Academy of Sciences, 116(9), 3488-3493.

Liu, Y. Z., Wang, Y. X., \& Jiang, C. L. (2017). Inflammation: the common pathway of stress-related diseases. Frontiers in Human Neuroscience, 11, 316.

Lopresti, A. L. (2017). Cognitive behaviour therapy and inflammation: A systematic review of its relationship and the potential implications for the treatment of depression. Australian \& New Zealand Journal of Psychiatry, 51(6), 565-582.

Lucas, R. E. (2007). Adaptation and the set-point model of subjective well-being: Does happiness change after major life events?. Current Directions in Psychological Science, 16(2), 75-79.

Lueken, U., \& Hahn, T. (2016). Functional neuroimaging of psychotherapeutic processes in anxiety and depression: from mechanisms to predictions. Current Opinion in Psychiatry, 29(1), 25-31.

Luhmann, M., Hofmann, W., Eid, M., \& Lucas, R. E. (2012). Subjective well-being and adaptation to life events: A meta-analysis on differences between cognitive and affective well-being. Journal of Personality and Social Psychology, 102, 592-615.

Lyubomirsky, S., Layous, K., Chancellor, J., \& Nelson, S. K. (2015). Thinking about rumination: The scholarly contributions and intellectual legacy of Susan NolenHoeksema. Annual Review of Clinical Psychology, 11, 1-22.

Maner, J. K., Miller, S. L., Schmidt, N. B., \& Eckel, L. A. (2010). The endocrinology of exclusion: rejection elicits motivationally tuned changes in progesterone. Psychological Science, 21(4), 581-588.

Marsland, A. L., Walsh, C., Lockwood, K., \& John-Henderson, N. A. (2017). The effects of acute psychological stress on circulating and stimulated inflammatory markers: a systematic review and meta-analysis. Brain, Behavior, and Immunity, 64, 208-219.

Martelli, A. M., Chester, D. S., Warren Brown, K., Eisenberger, N. I., \& Nathan DeWall, C. (2018). When Less is More: Mindfulness Predicts Adaptive Affective Responding to 
Rejection via Reduced Prefrontal Recruitment. Social Cognitive and Affective Neuroscience.

Mavros, M. N., Athanasiou, S., Gkegkes, I. D., Polyzos, K. A., Peppas, G., \& Falagas, M. E. (2011). Do psychological variables affect early surgical recovery?. PloS one, 6(5), e20306.

McEwen, B. S. (2016). In pursuit of resilience: stress, epigenetics, and brain plasticity. Annals of the New York Academy of Sciences, 1373(1), 56-64.

McEwen, B. S. (2018). Redefining neuroendocrinology: epigenetics of brain-body communication over the life course. Frontiers in Neuroendocrinology, 49, 8-30.

McGowan, P.O., Sasaki, A., D'Alessio, A.C., Dymov, S., Labonte, B., Szyf, M., et al. (2009). Epigenetic regulation of the glucocorticoid receptor in human brain associates with childhood abuse. Nature Neuroscience, 12, 342-348.

Medic, G., Wille, M., \& Hemels, M. E. (2017). Short-and long-term health consequences of sleep disruption. Nature and Science of Sleep, 9, 151.

Miller, G. (2011). Social neuroscience. Why loneliness is hazardous to your health. Science, 331, 138-40.

Miller, G., Rohleder, N., \& Cole, S. W. (2009). Chronic interpersonal stress predicts activation of pro-and anti-inflammatory signaling pathways six months later. Psychosomatic Medicine, 71(1), 57.

Moons, P., Luyckx, K., Dezutter, J., Kovacs, A. H., Thomet, C., Budts, W., et al. (2019). Religion and spirituality as predictors of patient-reported outcomes in adults with congenital heart disease around the globe. International Journal of Cardiology, 274, 9399 .

Moore, S. M., Diener, E., \& Tan, K. (2018). Using multiple methods to more fully understand causal relations: Positive affect enhances social relationships. In E. Diener, S. Oishi, \& L. Tay (Eds.), Handbook of well-being. Salt Lake City, UT: DEF Publishers.

Mulligan, C. J. (2016). Early environments, stress, and the epigenetics of human health. Annual Review of Anthropology, 45, 233-249.

Ngandu, T., von Strauss, E., Helkala, E.L., Winblad, B., Nissinen, A., Tuomilehto, J., et al. (2007). Education and dementia: what lies behind the association? Neurology, 69, $1442-1450$.

OECD: Organisation for Economic Co-operation and Development. (2013). OECD guidelines on measuring subjective well-being (Paris: OECD Publishing). 
Olatunji, B. O., Davis, M. L., Powers, M. B., \& Smits, J. A. (2013). Cognitive-behavioral therapy for obsessive-compulsive disorder: A meta-analysis of treatment outcome and moderators. Journal of psychiatric research, 47(1), 33-41.

Ortiz, J. B., \& Conrad, C. D. (2018). The impact from the aftermath of chronic stress on hippocampal structure and function: is there a recovery?. Frontiers in Neuroendocrinology.

Ortiz, R., \& Sibinga, E. M. (2017). The role of mindfulness in reducing the adverse effects of childhood stress and trauma. Children, 4(3), 16.

Park, C. L., Masters, K. S., Salsman, J. M., Wachholtz, A., Clements, A. D., SalmoiragoBlotcher, E., et al. (2017). Advancing our understanding of religion and spirituality in the context of behavioral medicine. Journal of Behavioral Medicine, 40(1), 39-51.

Park, D. C., \& Huang, C. M. (2010). Culture wires the brain: A cognitive neuroscience perspective. Perspectives on Psychological Science, 5(4), 391-400.

Perestelo-Perez, L., Barraca, J., Peñate, W., Rivero-Santana, A., \& Alvarez-Perez, Y. (2017). Mindfulness-based interventions for the treatment of depressive rumination: Systematic review and meta-analysis. International Journal of Clinical and Health Psychology, 17(3), 282-295.

Perkins, A., Ridler, J., Browes, D., Peryer, G., Notley, C., \& Hackmann, C. (2018). Experiencing mental health diagnosis: a systematic review of service user, clinician, and carer perspectives across clinical settings. The Lancet Psychiatry, 5(9), 747-764.

Petrie, K. J., \& Rief, W. (2019). Psychobiological mechanisms of placebo and nocebo effects: pathways to improve treatments and reduce side effects. Annual review of psychology, 70, 599-625.

Phillips, A. C. (2011). Psychosocial influences on vaccine responses. Social and Personality Psychology Compass, 5(9), 621-633.

Pietromonaco, P. R., \& Collins, N. L. (2017). Interpersonal mechanisms linking close relationships to health. American Psychologist, 72, 531- 542.

Pinto, J. V., Moulin, T. C., \& Amaral, O. B. (2017). On the transdiagnostic nature of peripheral biomarkers in major psychiatric disorders: a systematic review. Neuroscience \& Biobehavioral Reviews.

Pitschel-Walz, G., Leucht, S., Bäuml, J., Kissling, W., \& Engel, R. R. (2001). The effect of family interventions on relapse and rehospitalization in schizophrenia - a metaanalysis. Schizophrenia Bulletin, 27(1), 73-92. 
Posner, M. I., Tang, Y. Y., \& Lynch, G. (2014). Mechanisms of white matter change induced by meditation training. Frontiers in psychology, 5, 1220.

Qiu, C., Kivipelto, M., \& von Strauss, E. (2009). Epidemiology of Alzheimer's disease: occurrence, determinants, and strategies toward intervention, Dialogues in Clinical Neuroscience, 11(2):111-28.

Querstret, D., \& Cropley, M. (2013). Assessing treatments used to reduce rumination and/or worry: A systematic review. Clinical Psychology Review, 33, 996-1009.

Raichle, M. E., MacLeod, A. M., Snyder, A. Z., Powers, W. J., Gusnard, D. A., \& Shulman, G. L. (2001). A default mode of brain function. Proceedings of the National Academy of Sciences, 98(2), 676-682.

Reinares, M., Bonnín, C. M., Hidalgo-Mazzei, D., Sánchez-Moreno, J., Colom, F., \& Vieta, E. (2016). The role of family interventions in bipolar disorder: A systematic review. Clinical Psychology Review, 43, 47-57.

Roemer, L., Williston, S. K., \& Rollins, L. G. (2015). Mindfulness and emotion regulation. Current Opinion in Psychology, 3, 52-57.

Rook, K. S. (2015). Social networks in later life: Weighing positive and negative effects on health and well-being. Current Directions in Psychological Science, 24(1), 45-51.

Russell, A. L., Tasker, J. G., Lucion, A. B., Fiedler, J., Munhoz, C. D., Wu, T. Y. J., et al. (2018). Factors promoting vulnerability to dysregulated stress reactivity and stress-related disease. Journal of Neuroendocrinology, 30(10), e12641.

Russell-Williams, J., Jaroudi, W., Perich, T., Hoscheidt, S., El Haj, M., \& Moustafa, A. A. (2018). Mindfulness and meditation: treating cognitive impairment and reducing stress in dementia. Reviews in the Neurosciences, 29(7), 791-804.

Ryan, R. M., \& Deci, E. L. (2001). On happiness and human potentials: A review of research on hedonic and eudaimonic well-being. Annual Review of Psychology, 52(1), $141-166$.

Ryff, C.D. (2018). Eudaimonic Well-being: Highlights from 25 Years of Inquiry. In Diversity in Harmony-Insights from Psychology: Proceedings of the 31st International Congress of Psychology (Chichester, UK: John Wiley \& Sons, Ltd).

Saad, M., de Medeiros, R., \& Mosini, A. (2017). Are We Ready for a True Biopsychosocial-Spiritual Model? The Many Meanings of "Spiritual". Medicines, 4(4), 79. 
Sajeev, G., Weuve, J., Jackson, J. W., VanderWeele, T. J., Bennett, D. A., Grodstein, F., et al. (2016). Late-life cognitive activity and dementia: a systematic review and bias analysis. Epidemiology, 27(5), 732.

Sale, A., Berardi, N., \& Maffei, L. (2014). Environment and brain plasticity: towards an endogenous pharmacotherapy. Physiological Reviews, 94(1), 189-234.

Sandin, S., Lichtenstein, P., Kuja-Halkola, R., Hultman, C., Larsson, H., \& Reichenberg, A. (2017). The heritability of autism spectrum disorder. JAMA, 318(12), 1182-1184.

Sankar, A., Melin, A., Lorenzetti, V., Horton, P., Costafreda, S. G., \& Fu, C. H. (2018). A systematic review and meta-analysis of the neural correlates of psychological therapies in major depression. Psychiatry Research: Neuroimaging, 279, 31-39.

Santarnecchi, E., D’Arista, S., Egiziano, E., Gardi, C., Petrosino, R., Vatti, G., et al. (2014). Interaction between neuroanatomical and psychological changes after mindfulness-based training. PloS one, 9(10), e108359.

Santarnecchi, E., Del Bianco, C., Sicilia, I., Momi, D., Di Lorenzo, G., Ferrone, S., et al. (2018). Age of Insomnia Onset Correlates with a Reversal of Default Mode Network and Supplementary Motor Cortex Connectivity. Neural Plasticity, 2018.

Shaffer, J. (2016). Neuroplasticity and clinical practice: building brain power for health. Frontiers in psychology, 7, 1118.

Sheline, Y. I., Barch, D. M., Price, J. L., Rundle, M. M., Vaishnavi, S. N., Snyder, A. Z., et al. (2009). The default mode network and self-referential processes in depression. Proceedings of the National Academy of Sciences, 106(6), 1942-1947.

Simon, R., \& Engström, M. (2015). The default mode network as a biomarker for monitoring the therapeutic effects of meditation. Frontiers in psychology, 6, 776.

Simon, R., Pihlsgård, J., Berglind, U., Söderfeldt, B., \& Engström, M. (2017). Mantra meditation suppression of default mode beyond an active task: a pilot study. Journal of Cognitive Enhancement, 1(2), 219-227.

Slavish, D. C., Graham-Engeland, J. E., Smyth, J. M., \& Engeland, C. G. (2015). Salivary markers of inflammation in response to acute stress. Brain, Behavior, and Immunity, 44, 253-269.

Slopen, N., McLaughlin, K. A., \& Shonkoff, J. P. (2014). Interventions to improve cortisol regulation in children: a systematic review. Pediatrics, 133(2), 312-326.

Sprooten, E., Rasgon, A., Goodman, M., Carlin, A., Leibu, E., Lee, W. H., et al. (2017). Addressing reverse inference in psychiatric neuroimaging: Meta-analyses of task-related brain activation in common mental disorders. Human Brain Mapping, 38(4), 1846-1864. 
Stahl, S. M. (2012). Psychotherapy as an epigenetic 'drug': psychiatric therapeutics target symptoms linked to malfunctioning brain circuits with psychotherapy as well as with drugs. Journal of Clinical Pharmacy and Therapeutics, 37(3), 249-253.

Stavropoulos, K.K.M. (2017). Using neuroscience as an outcome measure for behavioral interventions in autism spectrum disorders (ASD): A review. Research in Autism Spectrum Disorders, 35, 62-73.

Steptoe, A., Hamer, M., \& Chida, Y. (2007). The effects of acute psychological stress on circulating inflammatory factors in humans: a review and meta-analysis. Brain, behavior, and immunity, 21(7), 901-912.

Steptoe, A., Deaton, A., \& Stone, A. A. (2015). Subjective wellbeing, health, and aging. The Lancet, 385, 640-648.

Straub, R. H., \& Cutolo, M. (2018). Psychoneuroimmunology-developments in stress research. Wiener Medizinische Wochenschrift, 168(3-4), 76-84.

Tashjian, S. M., Goldenberg, D., Monti, M. M., \& Galván, A. (2018). Sleep quality and adolescent default mode network connectivity. Social Cognitive and Affective Neuroscience, 13(3), 290-299.

Taylor, V. A., Daneault, V., Grant, J., Scavone, G., Breton, E., Roffe-Vidal, S., et al. (2012). Impact of meditation training on the default mode network during a restful state. Social Cognitive and Affective Neuroscience, 8(1), 4-14.

Tomlinson, E. R., Yousaf, O., Vittersø, A. D., \& Jones, L. (2017). Dispositional mindfulness and psychological health: a systematic review. Mindfulness, 1-21.

Turnwald, B. P., Goyer, J. P., Boles, D. Z., Silder, A., Delp, S. L., \& Crum, A. J. (2019). Learning one's genetic risk changes physiology independent of actual genetic risk. Nature Human Behaviour, 3(1), 48.

Tyler, C.W. \& Last, J.M. (1991). Epidemiology. Maxcy-Rosenau-Last Public Health and Preventive Medicine. 13th ed. (Norwalk, CT: Appleton \& Lange).

Uchino, B. N., Trettevik, R., Kent de Grey, R. G., Cronan, S., Hogan, J., \& Baucom, B. R. (2018). Social support, social integration, and inflammatory cytokines: A metaanalysis. Health Psychology.

Uher, R., \& Zwicker, A. (2017). Etiology in psychiatry: embracing the reality of polygene-environmental causation of mental illness. World Psychiatry, 16(2), 121-129. 
Valk, S. L., Bernhardt, B. C., Trautwein, F. M., Böckler, A., Kanske, P., Guizard, N., et al. (2017). Structural plasticity of the social brain: Differential change after socioaffective and cognitive mental training. Science Advances, 3(10), e1700489.

van der Velden, A. M., Kuyken, W., Wattar, U., Crane, C., Pallesen, K. J., Dahlgaard, J., et al. (2015). A systematic review of mechanisms of change in mindfulness-based cognitive therapy in the treatment of recurrent major depressive disorder. Clinical Psychology Review, 37, 26-39.

Van Hecke, A. V., Stevens, S., Carson, A. M., Karst, J. S., Dolan, B., Schohl, K., et al. (2015). Measuring the plasticity of social approach: a randomized controlled trial of the effects of the PEERS intervention on EEG asymmetry in adolescents with autism spectrum disorders. Journal of Autism and Developmental Disorders, 45, 316-335.

Varese, F., Smeets, F., Drukker, M., Lieverse, R., Lataster, T., Viechtbauer, W., et al. (2012). Childhood adversities increase the risk of psychosis: a meta-analysis of patientcontrol, prospective-and cross-sectional cohort studies. Schizophrenia Bulletin, 38(4), 661-671.

Verkuil, B., Brosschot, J. F., Gebhardt, W. A., \& Thayer, J. F. (2010). When worries make you sick: a review of perseverative cognition, the default stress response and somatic health. Journal of Experimental Psychopathology, 1(1), jep-009110.

von Bertanlaffy L (1975). Perspectives on General System Theory. New York, NY: George Braziller, Inc.

Wade, D. T., \& Halligan, P. W. (2017). The biopsychosocial model of illness: a model whose time has come. Clinical Rehabilitation, 31(8):995-1004.

Wallace, B. A., \& Shapiro, S. L. (2006). Mental balance and well-being: building bridges between Buddhism and Western psychology. The American Psychologist, 61(7), 690.

Wand, T. (2019). Is it time to end our complicity with pharmacocentricity?. International journal of mental health nursing, 28(1), 3-6.

Wang, K., Wei, D., Yang, J., Xie, P., Hao, X., \& Qiu, J. (2015). Individual differences in rumination in healthy and depressive samples: association with brain structure, functional connectivity and depression. Psychological Medicine, 45(14), 2999-3008.

Ward, A. M., McLaren, D. G., Schultz, A. P., Chhatwal, J., Boot, B. P., Hedden, T., et al. (2013). Daytime sleepiness is associated with decreased default mode network connectivity in both young and cognitively intact elderly subjects. Sleep, 36(11), 16091615.

Watkins, E. (2015). Psychological treatment of depressive rumination. Current Opinion in Psychology, 4, 32-36. 
Werner, S. (2012). Subjective well-being, hope, and needs of individuals with serious mental illness. Psychiatry Research, 196(2-3), 214-219.

Whitfield-Gabrieli, S., \& Ford, J. M. (2012). Default mode network activity and connectivity in psychopathology. Annual Review of Clinical Psychology, 8, 49-76.

Wirtz, P. H., \& von Känel, R. (2017). Psychological stress, inflammation, and coronary heart disease. Current Cardiology Reports, 19(11), 111.

Wood BL, Miller BD, Lehman HK. Review of family relational stress and pediatric asthma: the value of biopsychosocial systemic models. Fam Process. 2015;54: 376-389.

Yang, Y. D., Allen, T., Abdullahi, S. M., Pelphrey, K. A., Volkmar, F. R., \& Chapman, S. B. (2018). Neural mechanisms of behavioral change in young adults with highfunctioning autism receiving virtual reality social cognition training: A pilot study. Autism Research, 11(5), 713-725.

Yates, L. A., Ziser, S., Spector, A., \& Orrell, M. (2016). Cognitive leisure activities and future risk of cognitive impairment and dementia: Systematic review and metaanalysis. International psychogeriatrics, 28(11), 1791-1806.

Yu, J. H., Kim, M., Seo, J. H., \& Cho, S. R. (2016). Brain Plasticity and Neurorestoration by Environmental Enrichment. Brain \& Neurorehabilitation, 9(2).

Zhu, X., Zhu, Q., Shen, H., Liao, W., \& Yuan, F. (2017). Rumination and default mode network subsystems connectivity in first-episode, drug-naive young patients with major depressive disorder. Scientific Reports, 7, 43105.

Zoccola, P. M., \& Dickerson, S. S. (2012). Assessing the relationship between rumination and cortisol: A review. Journal of Psychosomatic Research, 73(1), 1-9.

Zubenko, G. S., Sommer, B. R., \& Cohen, B. M. (2018). On the Marketing and Use of Pharmacogenetic Tests for Psychiatric Treatment. JAMA psychiatry. 